\title{
Shape design sensitivity analysis with respect to the positioning of features in composite structures using the boundary element method
}

DOI:

10.1016/j.enganabound.2005.08.003

\section{Document Version}

Accepted author manuscript

Link to publication record in Manchester Research Explorer

Citation for published version (APA):

Tafreshi, A. (2006). Shape design sensitivity analysis with respect to the positioning of features in composite structures using the boundary element method. Engineering Analysis with Boundary Elements, 30(1), 1-13. https://doi.org/10.1016/j.enganabound.2005.08.003

Published in:

Engineering Analysis with Boundary Elements

\section{Citing this paper}

Please note that where the full-text provided on Manchester Research Explorer is the Author Accepted Manuscript or Proof version this may differ from the final Published version. If citing, it is advised that you check and use the publisher's definitive version.

\section{General rights}

Copyright and moral rights for the publications made accessible in the Research Explorer are retained by the authors and/or other copyright owners and it is a condition of accessing publications that users recognise and abide by the legal requirements associated with these rights.

\section{Takedown policy}

If you believe that this document breaches copyright please refer to the University of Manchester's Takedown Procedures [http://man.ac.uk/04Y6Bo] or contact uml.scholarlycommunications@manchester.ac.uk providing relevant details, so we can investigate your claim.

\section{OPEN ACCESS}


Tafreshi, A. Jan 2006 In : Engineering Analysis with Boundary Elements. 30, 1, p. 1-13 12 p.

\title{
SHAPE DESIGN SENSITIVITY ANALYSIS WITH RESPECT TO THE POSITIONING OF FEATURES IN COMPOSITE STRUCTURES USING THE BOUNDARY ELEMENT METHOD
}

\author{
Azam Tafreshi $\quad$ School of Mechanical, Aerospace and Civil Engineering, MACE \\ The University of Manchester, P.O.Box 88, Sackville Street \\ Manchester M60 1QD \\ azam.tafreshi@manchester.ac.uk
}

\section{ABSTRACT}

This paper presents the application of the boundary element method to the shape design sensitivity analysis of composite structures with holes and cutouts. A two-dimensional anisotropic domain which contains a number of voids of arbitrary shapes will be considered. The objective is to perform the design sensitivity analysis of the structure with respect to the translation and rotation of the voids using the boundary element method. A directly differentiated form of the boundary integral equation, with respect to geometric design variables is used to calculate the shape design sensitivities for anisotropic materials. The response sensitivity analysis, with respect to the design variables such as feature positions and orientations, is achieved by the definition of appropriate design velocity fields for these variables. To find the optimum positions of the features within an anisotropic structure with the highest stiffness, the elastic compliance of the structure has been minimized subject to constraints upon stresses and geometry. Due to the non-linear nature of the mean compliance and stresses, the numerical optimisation algorithm used is the feasible direction method, together with the golden section method for the one-dimensional search. A couple of test cases have been performed to verify the proposed method.

KEY WORDS: Shape optimisation, boundary element method, composites, design sensitivity analysis, anisotropic materials, minimum compliance, optimum positioning of features

\section{INTRODUCTION}

Laminated composites are gaining importance in aircraft structural applications because of their attractive performance characteristics, e.g. high strength-to-weight ratio, high stiffness-to-weight 
Tafreshi, A. Jan 2006 In : Engineering Analysis with Boundary Elements. 30, 1, p. 1-13 12 p. ratio, superior fatigue properties, and high corrosion resistance. The phenomenon of progressive failure in laminated composite structures is yet to be understood, and as a result, reliable strategies for designing optimal composite structures for desired life and strength are in demand. The analytical formulation of two- and three-dimensional anisotropic elasticity, using the finite element method or boundary integral equation techniques(BIE), has been well developed in the last three decades. This paper discusses the shape design sensitivities of two-dimensional anisotropic structures with respect to the positioning and orientation of their holes and cutouts.

In a project sponsored by the United Kingdom Atomic Energy Authority (UKAEA), two general purpose computer programs using the BEM [1-4] for shape optimisation of isotropic structures; weight minimization and maximum stress minimization, respectively, were developed. In 1990, [1] it represented a novel application of the boundary element method to practical design optimisation problems, and showed great potential for further development in the field of design optimisation.

The BEM, being a boundary oriented technique, can overcome a number of the difficulties associated with its main rival, the finite element method (FEM). In respect of the continuously changing geometry, the accuracy of the FE analysis using an initial mesh of elements may become inadequate during the optimisation process. If during the optimisation process, the finite element mesh has to be re-generated, the cost is relatively high. The sensitivity analysis in the calculation of the derivatives, with respect to the design variables, may be obtained directly [1] in the boundary element approach rather than by approximate methods, such as finite difference schemes. 
Tafreshi, A. Jan 2006 In : Engineering Analysis with Boundary Elements. 30, 1, p. 1-13 12 p.

In a study by the author[5], a directly differentiated form of the boundary integral equation, with respect to boundary point coordinates, was used to calculate stress and displacement derivatives for $2 \mathrm{D}$ anisotropic structures. The accuracy was compared with the results of the finite difference applied to the boundary element analysis. Not surprisingly, the results obtained by analytical differentiation are much more accurate. In another study by the author[6], the weight minimization of anisotropic structures with stress constraints using the BEM is presented. The design sensitivity analysis using the BEM was combined with an optimisation algorithm to form an optimum shape design program for anisotropic structures. Different materials were analysed to investigate the effect of engineering constants on the optimum shape design of the components.

In a recent study by the author[7], the optimal shape design of an anisotropic elastic body of maximum stiffness and minimum weight under specified loadings and using the boundary element method, was obtained. The elastic compliance of the structure was minimized while there were constraints on the maximum stress and weight of the structure. To demonstrate the effectiveness of this procedure, a series of design problems were analysed and discussed in detail. These results were compared with those results which were obtained with just minimizing the weight subject to stress and geometrical constraints[6].

It should be noted that to the author's knowledge, no other publications are available on the shape optimisation of composite materials using the boundary element method.

The objective of this work is directed towards the optimal positioning of features in anisotropic structures, using the boundary element method, for maximum stiffness while the weight remains unchanged. The elastic compliance will be minimized while there are constraints on the maximum stress and the geometry of the structure. Design sensitivity analysis, which is the 
Tafreshi, A. Jan 2006 In : Engineering Analysis with Boundary Elements. 30, 1, p. 1-13 12 p. calculation of quantitative information for how the response of a structure is affected by changes in the design variables that define its shape, has been validated through test cases with known solutions. To demonstrate the effectiveness of this procedure, a couple of design problems will be analysed and discussed in detail.

\section{$1.1 \quad$ NOTATION}

$\mathrm{a}_{\mathrm{mn}} \quad$ Elastic compliance matrix

$$
\begin{aligned}
& a_{11}=\frac{1}{E_{1}}, a_{12}=-\frac{v_{12}}{E_{1}}=-\frac{v_{21}}{E_{2}}, a_{16}=\frac{\eta_{12,1}}{E_{1}}=\frac{\eta_{1,12}}{G_{12}}, a_{22}=\frac{1}{E_{2}}, \\
& a_{26}=\frac{\eta_{12,2}}{E_{2}}=\frac{\eta_{2,12}}{G_{12}}, a_{66}=\frac{1}{G_{12}}
\end{aligned}
$$

$\mathrm{A}_{\mathrm{jk}} \quad$ Complex constants

$\mathrm{C}_{\mathrm{jk}}(\mathrm{P}) \quad$ The limiting value of the surface integral of $\mathrm{T}_{\mathrm{jk}}(\mathrm{P}, \mathrm{Q})$

$\mathrm{D}_{\mathrm{s}}(\mathrm{s}=1,4) \quad$ Operator

$\mathrm{E}_{\mathrm{k}} \quad$ Young's modulus in the $\mathrm{x}_{\mathrm{k}}$ direction

$\mathrm{E}_{\mathrm{s}} \quad$ Elastic compliance

$\left(\mathrm{E}_{\mathrm{s}}\right)_{0} \quad$ Elastic compliance at initial step

F Objective function

$\mathrm{F}_{0} \quad$ Objective function at initial step

$\mathrm{G}_{12} \quad$ Shear modulus

$\mathrm{g}_{\mathrm{j}}(\mathrm{X}) \quad$ Inequality constraints

$\mathrm{J}(\xi) \quad$ Jacobian of transformation from global Cartesian coordinates

to intrinsic coordinates of the element

$\mathrm{m}_{1 \mathrm{k}}, \mathrm{m}_{2 \mathrm{k}} \quad$ Unit vectors tangent and normal to the surface

$\mathrm{n}_{1}, \mathrm{n}_{2} \quad$ Direction cosines of the unit outward normal vector to the surface of the elastic body

$\mathrm{N}^{\mathrm{c}}(\xi) \quad$ Quadratic shape function corresponding to the cth node of the 
Tafreshi, A. Jan 2006 In : Engineering Analysis with Boundary Elements. 30, 1, p. 1-13 12 p.

Element

OXY Global coordinate system

$\mathrm{o} \tau_{\mathrm{i}} \omega_{\mathrm{i}} \quad$ Local coordinate system of each void

P Load point at the surface of the elastic domain

Q Field point at the surface of the elastic domain

$\mathrm{r}_{\mathrm{jk}} \quad$ Complex constants

s The domain boundary

$\mathrm{s}_{\mathrm{b}} \quad$ bth-element of the discretized boundary

$\mathrm{t}_{\mathrm{j}} \quad$ Traction vector

$\mathrm{T}_{\mathrm{jk}}(\mathrm{P}, \mathrm{Q}) \quad$ The jth component of the traction vector at point $\mathrm{Q}$ due

to a unit point load in the kth direction at $\mathrm{P}$

$\mathrm{u}_{\mathrm{j}} \quad$ Displacement vector

$\mathrm{U}_{\mathrm{jk}} \quad$ The jth component of the displacement vector at point $\mathrm{Q}$ due

to a unit point load in the kth direction at $\mathrm{P}$

X $\quad \mathrm{X}_{\mathrm{i}}=\left[\mathrm{X}_{1}, \mathrm{X}_{2}, \ldots ., \mathrm{X}_{\mathrm{n}}\right]^{\mathrm{T}} ;$ design variable vector

$\mathrm{x}_{\mathrm{i}} \quad$ Rectangular Cartesian coordinates

$\mathrm{z}_{\mathrm{j}} \quad$ Complex coordinates

$\alpha_{\mathrm{j}}, \beta_{\mathrm{j}} \quad$ Real constants

$\delta_{\mathrm{jk}} \quad$ Kronecker delta

$\varepsilon_{\mathrm{jk}} \quad$ Strain tensor

$\zeta_{\mathrm{i}} \quad$ Coordinates of load point

$\xi \quad$ Intrinsic coordinates of isoparametric quadratic element

$\eta_{\mathrm{jk}, 1}$ and $\eta_{1, \mathrm{jk}}$ Coefficients of mutual influence of the first and second kind, respectively

$\Lambda_{1}, \Lambda_{2} \quad$ Real functions of the cartesian and intrinsic coordinates at each integration point

$\mu_{\mathrm{s}}$

Roots of the characteristic equation 
Tafreshi, A. Jan 2006 In : Engineering Analysis with Boundary Elements. 30, 1, p. 1-13 12 p.

$\begin{array}{ll}v_{\mathrm{jk}} & \text { Poisson's ratio } \\ \overline{\mathrm{x}}_{1}, \overline{\mathrm{x}}_{2} & \text { Local coordinates on an element } \\ \sigma_{\mathrm{jk}} & \text { Stress tensor } \\ \sigma_{\max } & \text { Maximum equivalent stress } \\ \phi & \text { Airy stress function } \\ \psi & \text { Shape variable such as translational or rotational position of a typical void } \\ \Omega_{1}, \Omega_{2} & \text { Real functions of the cartesian and intrinsic coordinates at each integration } \\ & \text { point }\end{array}$

\section{CONSTITUTIVE EQUATIONS FOR PLANE ANISOTROPIC ELASTICITY}

Combining the stress-strain relations, the compatibility equation of strains and the equilibrium equation, the governing equation for the two dimensional problem of homogeneous and anisotropic elasticity can be obtained

$\mathrm{a}_{22} \frac{\partial^{4} \phi}{\partial \mathrm{x}_{1}^{4}}-2 \mathrm{a}_{26} \frac{\partial^{4} \phi}{\partial \mathrm{x}_{1}^{3} \partial \mathrm{x}_{2}}+\left(2 \mathrm{a}_{12}+\mathrm{a}_{66}\right) \frac{\partial^{4} \phi}{\partial \mathrm{x}_{1}^{2} \partial \mathrm{x}_{2}^{2}}-2 \mathrm{a}_{16} \frac{\partial^{4} \phi}{\partial \mathrm{x}_{1} \partial \mathrm{x}_{2}^{3}}+\mathrm{a}_{11} \frac{\partial^{4} \phi}{\partial \mathrm{x}_{2}^{4}}=0$

where $a_{m n}$ are the elastic compliances of the material which can be written in terms of elastic constants [8] and $\phi\left(\mathrm{x}_{1}, \mathrm{x}_{2}\right)$ is the Airy stress function in the $\mathrm{x}_{1}-\mathrm{x}_{2}$ plane. By introducing the operator $\mathrm{D}_{\mathrm{s}}(\mathrm{s}=1,4)$ as

$D_{s}=\frac{\partial}{\partial x_{2}}-\mu_{s} \frac{\partial}{\partial x_{1}}$

equation (1) becomes

$D_{1} D_{2} D_{3} D_{4}(\phi)=0$

and $\mu_{\mathrm{s}}$ are the four roots of the characteristic equation.

$\left[a_{22}-2 \mu a_{26}+\left(2 a_{12}+a_{66}\right) \mu^{2}-2 a_{16} \mu^{3}+a_{11} \mu^{4}\right] \frac{d^{4} \phi}{d z^{4}}=0$. 
Tafreshi, A. Jan 2006 In : Engineering Analysis with Boundary Elements. 30, 1, p. 1-13 12 p.

In order to have a solution for the stress function, the term in square brackets must be zero.

Lekhnitskii [9] has shown that for an anisotropic material, these roots are distinct and must be either purely imaginary or complex, and they may be denoted by

$\mu_{1}=\alpha_{1}+i \beta_{1} \quad, \quad \mu_{2}=\alpha_{2}+i \beta_{2} \quad, \quad \mu_{3}=\bar{\mu}_{1} \quad, \quad \mu_{4}=\bar{\mu}_{2}$

where $\alpha_{\mathrm{j}}$ and $\beta_{\mathrm{j}},(\mathrm{j}=1,2)$, are real constants, $i=\sqrt{-1}$ and the overbar represents the complex conjugate. The characteristic directions may thus be denoted by

$z_{j}=x_{1}+\mu_{j} x_{2} \quad j=1,2$

and their complex conjugates.

\section{REVIEW OF THE BOUNDARY ELEMENT METHOD FOR THE ANALYSIS OF ANISOTROPIC MATERIALS}

The boundary element method is based on the unit load solutions in an infinite body, known as the fundamental solutions, used with the reciprocal work theorem and appropriate limit operations. The boundary integral equation, in the direct formulation of the BEM for anisotropic materials, is an integral constraint equation relating the tractions $\left(\mathrm{t}_{\mathrm{j}}\right)$ and the displacements $\left(\mathrm{u}_{\mathrm{j}}\right)$ at the boundary $s$ of the homogeneous elastic domain and may be written as

$$
C_{j k} u_{j}(P)+\int_{s} T_{j k}(P, Q) u_{j}(Q) d s(Q)=\int_{s} U_{j k}(P, Q) t_{j}(Q) d s(Q) \quad j, k=1,2
$$

where $\mathrm{P}\left(\zeta_{1}, \zeta_{2}\right)$ and $\mathrm{Q}\left(\mathrm{x}_{1}, \mathrm{x}_{2}\right)$ are the load and field points, respectively. $\mathrm{U}_{\mathrm{jk}}(\mathrm{P}, \mathrm{Q})$ and $\mathrm{T}_{\mathrm{jk}}(\mathrm{P}, \mathrm{Q})$ are the fundamental solutions which represent the displacements and tractions, respectively, in the $\mathrm{x}_{\mathrm{k}}$ direction at $\mathrm{Q}$, due to a unit load in the $\mathrm{x}_{\mathrm{j}}$ direction at $\mathrm{P}$ in an infinite anisotropic body. The constant $\mathrm{C}_{\mathrm{jk}}$ depends on the local geometry of the boundary at $\mathrm{P}$, whether it lies on a smooth surface or a sharp corner. In terms of the generalised complex variables

$$
\begin{aligned}
& z_{1}=\left(x_{1}-\zeta_{1}\right)+\mu_{1}\left(x_{2}-\zeta_{2}\right) \\
& z_{2}=\left(x_{1}-\zeta_{1}\right)+\mu_{2}\left(x_{2}-\zeta_{2}\right)
\end{aligned}
$$

the fundamental solutions for displacements and tractions, respectively, are as follows: 
$U_{j k}=2 \operatorname{Re}\left[r_{k 1} A_{j 1} \ln \left(z_{1}\right)+r_{k 2} A_{j 2} \ln \left(z_{2}\right)\right]$

$T_{j 1}=2 n_{1} \operatorname{Re}\left[\mu_{1}^{2} A_{j 1} / z_{1}+\mu_{2}^{2} A_{j 2} / z_{2}\right]-2 n_{2} \operatorname{Re}\left[\mu_{1} A_{j 1} / z_{1}+\mu_{2} A_{j 2} / z_{2}\right]$

$T_{j 2}=-2 n_{1} \operatorname{Re}\left[\mu_{1} A_{j 1} / z_{1}+\mu_{2} A_{j 2} / z_{2}\right]+2 n_{2} \operatorname{Re}\left[A_{j 1} / z_{1}+A_{j 2} / z_{2}\right]$

where $\mathrm{n}_{\mathrm{j}}$ are the unit outward normal components at $\mathrm{Q}$, with respect to the $\mathrm{x}_{1}-\mathrm{x}_{2}$ coordinate system. The constants $r_{k j}$ are

$r_{1 j}=a_{11} \mu_{j}^{2}+a_{12}-a_{16} \mu_{j}$
$r_{2 j}=a_{12} \mu_{j}+a_{22} / \mu_{j}-a_{26}$

and $\mathrm{A}_{\mathrm{jk}}$ are complex constants which may be obtained from the following set of equations

$A_{j 1}-\bar{A}_{j 1}+A_{j 2}-\bar{A}_{j 2}=\delta_{j 2} / 2 \pi i$

$\mu_{1} A_{j 1}-\bar{\mu}_{1} \bar{A}_{j 1}+\mu_{2} A_{j 2}-\bar{\mu}_{2} \bar{A}_{j 2}=-\delta_{j 1} / 2 \pi i$

$r_{11} A_{j 1}-\bar{r}_{11} \bar{A}_{j 1}+r_{21} A_{j 2}-\bar{r}_{21} \bar{A}_{j 2}=0$.

$r_{12} A_{j 1}-\bar{r}_{12} \bar{A}_{j 1}+r_{22} A_{j 2}-\bar{r}_{22} \bar{A}_{j 2}=0$.

where $\delta_{\mathrm{jk}}$ is the Kronecker delta. For the details of these, the reader should refer to references [10-13].

The boundary element implementation of equation 7 entails boundary discretization. Quadratic isoparametric elements are chosen for the analyses. Substitution of these isoparametric representations into equation 7 will result in a set of linear algebraic equations for the unknown displacements and tractions at the nodes on the boundary of the solution domain as follows

$$
\mathrm{AU}=\mathrm{B}
$$

where $A$ is the final coefficient matrix, $U$ is a vector containing the unknown variables (displacements or tractions) and the second member $\mathrm{B}$ is a vector. $\mathrm{A}$ and $\mathrm{B}$ result after the rearrangement of the system of equations obtained from the substitution of the boundary conditions in the discretized version of equation 7. These linear algebraic equations may then be solved by standard matrix solution techniques.

To calculate surface stresses from the already calculated surface tractions and displacements, it is necessary to consider a local system of coordinates $\left(\bar{x}_{1}, \bar{x}_{2}\right)$. Let $\mathrm{m}_{1 \mathrm{k}}$ be the unit vector in the 
Tafreshi, A. Jan 2006 In : Engineering Analysis with Boundary Elements. 30, 1, p. 1-13 12 p.

direction tangential to the surface, and $\mathrm{m}_{2 \mathrm{k}}$ the one in the direction normal to the surface. Let $\overline{\mathrm{u}}_{\mathrm{j}}, \overline{\mathrm{t}}_{\mathrm{j}}, \bar{\varepsilon}_{\mathrm{jk}}$ and $\bar{\sigma}_{\mathrm{jk}}$ be the displacements, tractions, strains, and stresses, respectively, in the local coordinates. The displacement in the tangential direction is

$\overline{\mathrm{u}}_{1}(\xi)=\mathrm{N}^{\mathrm{c}}(\xi) \mathrm{u}_{\mathrm{k}}^{\mathrm{c}} \mathrm{m}_{1 \mathrm{k}}$

where $\mathbf{N}^{\mathrm{c}}(\xi)(\mathrm{c}=1,2,3)$ are the quadratic shape functions of intrinsic coordinates. The strain in the tangential direction is obtained by this expression to give

$\bar{\varepsilon}_{11}(\xi)=\frac{\mathrm{dN}^{\mathrm{c}}(\xi)}{\mathrm{d} \xi} \mathrm{u}_{\mathrm{k}}^{\mathrm{c}} \mathrm{m}_{1 \mathrm{k}} \frac{1}{\mathrm{~J}(\xi)}$

Then, using the constitutive equation, the components of the stress tensor in the local coordinate system can be calculated, and by a simple transformation, the stress components in the global system can be obtained.

\section{SHAPE DESIGN SENSITIVITY ANALYSIS OF 2D ANISOTROPIC STRUCTURES WITH HOLES AND CUTOUTS}

\subsection{Design velocity field}

The design velocity field describes the movements of the material points due to a change in the shape of the structural domain. If a relationship exists between the coordinates of a boundary point in the structure and the geometric/shape variable, then the design velocity term will be the derivative of the point position with respect to that variable.

Fig. 1 shows a continuum with a series of voids with arbitrary geometries. OXY is the global coordinate system which is fixed in space, and $\mathrm{o}_{\mathrm{k}} \omega_{\mathrm{k}} \tau_{\mathrm{k}}$ is the local coordinate system of each void. The objective of this study is to find the optimum position and orientation angle of each void with respect to the global coordinate system. Therefore, there are at most three shape variables associated with a typical void, the centre coordinates, and the orientation angle of the void's local coordinate system with respect to the global coordinate system. This is 
Tafreshi, A. Jan 2006 In : Engineering Analysis with Boundary Elements. 30, 1, p. 1-13 12 p. provided the shape, position and orientation of each void, with respect to its local coordinate system, remains unchanged.

Assume $T_{1}$ and $T_{2}$ are the translational positions in the $X$ and $Y$ directions, respectively, and $\theta$ is the angle of rotation of a typical void in a continuum, with respect to the global coordinate system. Therefore, for any point on the movable void

$$
x_{i}=\left(x_{i}\right)_{0}+T_{i}+\bar{R} \cos \theta \text { or } x_{i}=\left(x_{i}\right)_{0}+T_{i}+\bar{R} \sin \theta
$$

where $\left(\mathrm{x}_{\mathrm{i}}\right)_{0}$ is the original value of $\mathrm{x}_{\mathrm{i}} \cdot \bar{R}$ is the fixed distance between material point and the rotation axis.

The velocity field terms, for the above shape variables, when the movement of the void is translational $\left(\mathrm{T}_{\mathrm{i}}\right)$ can be written as

$$
x_{i}^{\prime}=1
$$

and when the movement of the void is rotational $(\theta)$ can be written as

$$
x_{i}^{\prime}=-\bar{R} \sin \theta \quad \text { or } \quad \bar{R} \cos \theta
$$

Now, consider that a function such as $\mathrm{F}$ is defined over the domain shown in Fig.1, and the boundaries of the domain are discretized to $\mathrm{M}$ quadratic boundary elements with $\mathrm{N}$ nodes. The material derivative $\mathrm{F}^{\prime}$ with respect to the geometric variable $\psi$ of a typical void, which can be translational $\left(T_{\mathrm{i}}\right)$ or rotational movement $(\theta)$, can be written as

$$
\frac{d F}{d \psi}=\frac{\partial F}{\partial \psi}+\frac{\partial F}{\partial x_{i}} \frac{\partial x_{i}}{\partial \psi}
$$

$\partial F / \partial \psi$ is equal to zero because the shape variables are not explicit terms in the boundary integral equation. The design velocity fields, $\partial x_{i} / \partial \psi$, can be obtained using equations 15-17. $\partial F / \partial x_{i}$ are derivatives of the function $\mathrm{F}$ with respect to the coordinates of the nodes located 
Tafreshi, A. Jan 2006 In : Engineering Analysis with Boundary Elements. 30, 1, p. 1-13 12 p. on the boundary of the movable void. In the present study, the function $\mathrm{F}$ is either the elastic compliance of the structure or the boundary stress. Therefore, the corresponding derivatives can be determined using the relations which are presented in the following sections.

\subsection{Implicit differentiation of the BIE equation with respect to the boundary point position}

Implicit differentiation of the BIE equation, with respect to a boundary point coordinate, $\mathrm{x}_{\mathrm{h}}(\mathrm{h}=1,2)$, results in the following equation

$$
\begin{aligned}
& C_{j k}(P) \frac{\partial u_{j}(P)}{\partial x_{h}}+\frac{\partial C_{j k}}{\partial x_{h}} u_{j}(P)+\int_{s}\left(\frac{\partial T_{j k}(P, Q)}{\partial x_{h}} u_{j}(Q)+T_{j k}(P, Q) \frac{\partial u_{j}(Q)}{\partial x_{h}}\right) d s(Q)+ \\
& \int_{s} T_{j k}(P, Q) u_{j}(Q) \frac{\partial(d s(Q))}{\partial x_{h}}=\int_{s}\left(\frac{\partial U_{j k}(P, Q)}{\partial x_{h}} t_{j}(Q)+U_{j k}(P, Q) \frac{\partial t_{j}(Q)}{\partial x_{h}}\right) d s(Q)+ \\
& \int_{s} U_{j k}(P, Q) t_{j}(Q) \frac{\partial(d s(Q))}{\partial x_{h}}
\end{aligned}
$$

The derivatives of the terms which only depend on the geometry will be carried out similar to the isotropic materials [1-4]. The derivatives of the remaining terms such as $U_{j k}$ and $T_{j k}$ for anisotropic materials will be as follows:

$$
\begin{aligned}
& \frac{\partial U_{j k}}{\partial x_{h}}=2 \frac{\partial}{\partial x_{h}}\left[\operatorname{Re}\left(r_{k 1} A_{j 1} \ln \left(z_{1}\right)+r_{k 2} A_{j 2} \ln \left(z_{2}\right)\right)\right] \\
& \frac{\partial T_{j 1}}{\partial x_{h}}=2 n_{1} \frac{\partial}{\partial x_{h}}\left[\operatorname{Re}\left(\frac{\mu_{1}^{2} A_{j 1}}{z_{1}}+\frac{\mu_{2}^{2} A_{j 2}}{z_{2}}\right)\right]+2 \operatorname{Re}\left(\frac{\mu_{1}^{2} A_{j 1}}{z_{1}}+\frac{\mu_{2}^{2} A_{j 2}}{z_{2}}\right) \frac{\partial\left(n_{1}\right)}{\partial x_{h}} \\
& -2 n_{2} \frac{\partial}{\partial x_{h}}\left[\operatorname{Re}\left(\frac{\mu_{1} A_{j 1}}{z_{1}}+\frac{\mu_{2} A_{j 2}}{z_{2}}\right)\right]-2 \operatorname{Re}\left(\frac{\mu_{1} A_{j 1}}{z_{1}}+\frac{\mu_{2} A_{j 2}}{z_{2}}\right) \frac{\partial\left(n_{2}\right)}{\partial x_{h}} \\
& \frac{\partial T_{j 2}}{\partial x_{h}}=-2 n_{1} \frac{\partial}{\partial x_{h}}\left[\operatorname{Re}\left(\frac{\mu_{1} A_{j 1}}{z_{1}}+\frac{\mu_{2} A_{j 2}}{z_{2}}\right)\right]-2 \operatorname{Re}\left(\frac{\mu_{1} A_{j 1}}{z_{1}}+\frac{\mu_{2} A_{j 2}}{z_{2}}\right) \frac{\partial\left(n_{1}\right)}{\partial x_{h}} \\
& +2 n_{2} \frac{\partial}{\partial x_{h}}\left[\operatorname{Re}\left(\frac{A_{j 1}}{z_{1}}+\frac{A_{j 2}}{z_{2}}\right)\right]+2 \operatorname{Re}\left(\frac{A_{j 1}}{z_{1}}+\frac{A_{j 2}}{z_{2}}\right) \frac{\partial\left(n_{2}\right)}{\partial x_{h}}
\end{aligned}
$$


Tafreshi, A. Jan 2006 In : Engineering Analysis with Boundary Elements. 30, 1, p. 1-13 12 p.

where the coefficients $\mu_{\mathrm{j}}$ and $\mathrm{A}_{\mathrm{jk}}$ depend on the material properties and are independent of the boundary nodes coordinates. To calculate the preceding derivatives, the complex values,

$\ln \left(z_{j}\right)$ and $\frac{1}{z_{j}}$, can be written as

$\ln \left(z_{j}\right)=\ln \left|z_{j}\right|+i \arg \left(z_{j}\right)$

$\frac{1}{z_{j}}=\frac{\bar{z}_{j}}{\left|z_{j}\right|^{2}}$

Defining the real functions $\Lambda_{\mathrm{j}}$ and $\Omega_{\mathrm{j}}$ as

$$
\begin{aligned}
& \Lambda_{1}=\left(x_{1}-\zeta_{1}\right)+\alpha_{1}\left(x_{2}-\zeta_{2}\right) \\
& \Lambda_{2}=\left(x_{1}-\zeta_{1}\right)+\alpha_{2}\left(x_{2}-\zeta_{2}\right) \\
& \Omega_{1}=-\beta_{1} \zeta_{2}+\beta_{1} x_{2} \\
& \Omega_{2}=-\beta_{2} \zeta_{2}+\beta_{2} x_{2}
\end{aligned}
$$

The complex coordinates and their conjugates can be written as

$$
z_{j}=\Lambda_{j}+i \Omega_{j}, \bar{z}_{j}=\Lambda_{j}-i \Omega_{j}
$$

By substituting equations 21-23 into equation 20 the derivatives of the kernel products with respect to the design variable $\mathrm{x}_{\mathrm{h}}$, can be obtained.

$$
\begin{aligned}
\frac{\partial U_{j k}}{\partial x_{h}}=2 \operatorname{Re}( & \left.r_{k 1} A_{j 1}\right) \frac{\partial}{\partial x_{h}}\left[\ln \left|z_{1}\right|\right]+2 \operatorname{Re}\left(r_{k 1} A_{j 1} i\right) \frac{\partial}{\partial x_{h}}\left[\arg \left(z_{1}\right)\right] \\
+ & 2 \operatorname{Re}\left(r_{k 2} A_{j 2}\right) \frac{\partial}{\partial x_{h}}\left[\ln \left|z_{2}\right|\right]+2 \operatorname{Re}\left(r_{k 2} A_{j 2} i\right) \frac{\partial}{\partial x_{h}}\left[\arg \left(z_{2}\right)\right]
\end{aligned}
$$


Tafreshi, A. Jan 2006 In : Engineering Analysis with Boundary Elements. 30, 1, p. 1-13 12 p.

$$
\begin{aligned}
& \frac{\partial T_{j 1}}{\partial x_{h}}=2 \operatorname{Re}\left[\frac{\mu_{1}^{2} A_{j 1}}{z_{1}}+\frac{\mu_{2}^{2} A_{j 2}}{z_{2}}\right] \frac{\partial n_{1}}{\partial x_{h}}-2 \operatorname{Re}\left[\frac{\mu_{1} A_{j 1}}{z_{1}}+\frac{\mu_{2} A_{j 2}}{z_{2}}\right] \frac{\partial n_{2}}{\partial x_{h}} \\
& +2 n_{1} \operatorname{Re}\left(\mu_{1}^{2} A_{j 1}\right) \frac{\partial}{\partial x_{h}}\left(\frac{\Lambda_{1}}{\left|z_{1}\right|^{2}}\right)+2 n_{1} \operatorname{Re}\left(-\mu_{1}^{2} A_{j 1} i\right) \frac{\partial}{\partial x_{h}}\left(\frac{\Omega_{1}}{\left|z_{1}\right|^{2}}\right)+2 n_{1} \operatorname{Re}\left(\mu_{2}^{2} A_{j 2}\right) \frac{\partial}{\partial x_{h}}\left(\frac{\Lambda_{2}}{\left|z_{2}\right|^{2}}\right) \\
& +2 n_{1} \operatorname{Re}\left(-\mu_{2}^{2} A_{j 2} i\right) \frac{\partial}{\partial x_{h}}\left(\frac{\Omega_{2}}{\left|z_{2}\right|^{2}}\right)-2 n_{2} \operatorname{Re}\left(\mu_{1} A_{j 1}\right) \frac{\partial}{\partial x_{h}}\left(\frac{\Lambda_{1}}{\left|z_{1}\right|^{2}}\right)-2 n_{2} \operatorname{Re}\left(-\mu_{1} A_{j 1} i\right) \frac{\partial}{\partial x_{h}}\left(\frac{\Omega_{1}}{\left|z_{1}\right|^{2}}\right) \\
& -2 n_{2} \operatorname{Re}\left(\mu_{2} A_{j 2}\right) \frac{\partial}{\partial x_{h}}\left(\frac{\Lambda_{2}}{\left|z_{2}\right|^{2}}\right)-2 n_{2} \operatorname{Re}\left(-\mu_{2} A_{j 2} i\right) \frac{\partial}{\partial x_{h}}\left(\frac{\Omega_{2}}{\left|z_{2}\right|^{2}}\right)
\end{aligned}
$$

$$
\begin{aligned}
& \frac{\partial T_{j 2}}{\partial x_{h}}=-2 \operatorname{Re}\left[\frac{\mu_{1} A_{j 1}}{z_{1}}+\frac{\mu_{2} A_{j 2}}{z_{2}}\right] \frac{\partial n_{1}}{\partial x_{h}}+2 \operatorname{Re}\left[\frac{A_{j 1}}{z_{1}}+\frac{A_{j 2}}{z_{2}}\right] \frac{\partial n_{2}}{\partial x_{h}} \\
& -2 n_{1} \operatorname{Re}\left(\mu_{1} A_{j 1}\right) \frac{\partial}{\partial x_{h}}\left(\frac{\Lambda_{1}}{\left|z_{1}\right|^{2}}\right)-2 n_{1} \operatorname{Re}\left(-i \mu_{1} A_{j 1}\right) \frac{\partial}{\partial x_{h}}\left(\frac{\Omega_{1}}{\left|z_{1}\right|^{2}}\right)-2 n_{1} \operatorname{Re}\left(\mu_{2} A_{j 2}\right) \frac{\partial}{\partial x_{h}}\left(\frac{\Lambda_{2}}{\left|z_{2}\right|^{2}}\right) \\
& -2 n_{1} \operatorname{Re}\left(-i \mu_{2} A_{j 2}\right) \frac{\partial}{\partial x_{h}}\left(\frac{\Omega_{2}}{\left|z_{2}\right|^{2}}\right)+2 n_{2} \operatorname{Re}\left[A_{j 1}\right] \frac{\partial}{\partial x_{h}}\left(\frac{\Lambda_{1}}{\left|z_{1}\right|^{2}}\right)+2 n_{2} \operatorname{Re}\left[-i A_{j 1}\right] \frac{\partial}{\partial x_{h}}\left(\frac{\Omega_{1}}{\left|z_{1}\right|^{2}}\right) \\
& +2 n_{2} \operatorname{Re}\left[A_{j 2}\right] \frac{\partial}{\partial x_{h}}\left(\frac{\Lambda_{2}}{\left|z_{2}\right|^{2}}\right)+2 n_{2} \operatorname{Re}\left(-i A_{j 2}\right) \frac{\partial}{\partial x_{h}}\left(\frac{\Omega_{2}}{\left|z_{2}\right|^{2}}\right)
\end{aligned}
$$

Therefore, the design sensitivity analysis is carried out by implicit differentiation of the structural response (equation 12) with respect to the coordinates of the boundary nodes of the movable void in the structure.

$$
\frac{\partial A}{\partial x_{h}} U+A \frac{\partial U}{\partial x_{h}}=\frac{\partial B}{\partial x_{h}} \quad \Rightarrow \quad A \frac{\partial U}{\partial x_{h}}=\left(\frac{\partial B}{\partial x_{h}}-\frac{\partial A}{\partial x_{h}} U\right)
$$

This is a set of linear algebraic equations for the unknown gradients, $\frac{\partial U}{\partial x_{h}}$, and equivalent to solving the same equation as 12 . Thus, if the quantity in brackets in equation 27 is separately 
assembled, then the derivative vector $\frac{\partial U}{\partial x_{h}}$, containing the derivatives of displacements or tractions, can be computed in one pass by re-entering the equation solver.

The gradients of stresses usually require the intermediate calculation of the gradients of displacements, with respect to the boundary nodes coordinates. For the derivatives of the stresses, both sides of equation (14) are differentiated and the gradients of strain in the tangential direction are obtained from

$$
\frac{\partial \bar{\varepsilon}_{11}}{\partial x_{h}}=\frac{d N^{c}(\xi)}{d \xi} \frac{\partial u_{k}^{c}}{\partial x_{h}} m_{1 k} \frac{1}{J(\xi)}+\frac{d N^{c}(\xi)}{d \xi} u_{k}^{c} \frac{\partial m_{1 k}}{\partial x_{h}} \frac{1}{J(\xi)}+\frac{d N^{c}(\xi)}{d \xi} u_{k}^{c} m_{1 k} \frac{-1}{[J(\xi)]^{2}} \frac{\partial[J(\xi)]}{\partial x_{h}}
$$

which is a function of the gradients of displacements previously calculated. The gradients of the stresses can then be determined by differentiating the constitutive equations for the anisotropic materials.

In reference [5], the derivatives of displacements and stresses, with respect to the coordinates of the boundary nodes for anisotropic materials, are calculated both by this direct analytical differentiation method and by the finite difference method. The former is shown to be both more accurate and less time consuming.

\subsection{Analytic calculation of elastic compliance and its derivatives}

The elastic compliance is evaluated as the strain energy of the structure

$$
E_{s}=\frac{1}{2} \int_{s} t_{j} u_{j} d s
$$

If the boundary of the structure is discretized to $\mathrm{M}$ quadaratic boundary elements, therefore, the elastic compliance can be evaluated as 
Tafreshi, A. Jan 2006 In : Engineering Analysis with Boundary Elements. 30, 1, p. 1-13 12 p.

$\mathrm{E}_{\mathrm{s}}=\frac{1}{2} \sum_{\mathrm{b}=1}^{\mathrm{M}} \int_{\mathrm{s}_{\mathrm{b}}}\left[\mathrm{t}_{\mathrm{j}}^{\mathrm{c}}(\xi) \mathrm{N}^{\mathrm{c}}(\xi)\right]\left[\mathrm{u}_{\mathrm{j}}^{\mathrm{d}}(\xi) \mathrm{N}^{\mathrm{d}}(\xi)\right] \mathrm{J}(\xi) \mathrm{d} \xi$

The derivatives of the elastic compliance, with respect to the boundary point coordinates $\mathrm{x}_{\mathrm{h}}$, can also be calculated analytically as shown below[7]

$$
\begin{gathered}
\frac{\partial E_{s}}{\partial x_{h}}=\frac{1}{2} \sum_{b=1}^{M} \int_{s_{b}}\left[\frac{t_{j}^{c}(\xi)}{d x_{h}} N^{c}(\xi)+t_{j}^{c}(\xi) \frac{d N^{c}(\xi)}{d x_{h}}\right]\left[u_{j}^{d}(\xi) N^{d}(\xi)\right] J(\xi) d \xi+ \\
\frac{1}{2} \sum_{b=1}^{M} \int_{s_{b}}\left[t_{j}^{c}(\xi) N^{c}(\xi)\right]\left[\frac{u_{j}^{d}(\xi)}{d x_{h}} N^{d}(\xi)+u_{j}^{d}(\xi) \frac{d N^{d}(\xi)}{d x_{h}}\right] J(\xi) d \xi+ \\
\frac{1}{2} \sum_{b=1}^{M} \int_{s_{b}}\left[t_{j}^{c}(\xi) N^{c}(\xi)\right]\left[u_{j}^{d}(\xi) N^{d}(\xi)\right] \frac{\partial J(\xi)}{d x_{h}} d \xi
\end{gathered}
$$

Equation (31) shows that in order to obtain the compliance derivatives, the derivatives of tractions and displacements must already be calculated. Therefore, during the analysis the compliance derivatives will be evaluated after the stresses, displacements and their derivatives are obtained.

In reference [6], the derivatives of elastic compliance, with respect to the coordinates of the boundary nodes for anisotropic materials, are calculated both by this direct analytical differentiation method and by the finite difference method. Obviously, the direct analytical differentiation is more accurate and less time consuming.

\section{PROBLEM STATEMENT AND METHOD OF OPTIMIZATION}

The shape optimisation problem can be stated mathematically as

$$
\begin{array}{ll}
\operatorname{Min}\left\{F\left(X_{1}\right\}\right. & 1=1,2,3, \ldots, n \\
\text { Subject to } g_{i}\left(X_{1}\right) \leq 0 . & i=1,2,3 \ldots \ldots, m \\
X_{1}^{L} \leq X_{1} \leq X_{1}^{U} &
\end{array}
$$


Tafreshi, A. Jan 2006 In : Engineering Analysis with Boundary Elements. 30, 1, p. 1-13 12 p.

in which $\mathrm{F}$ is the objective function and $\mathrm{g}_{\mathrm{i}}$ the constraint function describing the $i$ th structural response. $\mathrm{X}$ is a vector of design variables that defines the shape of the variable part of the structure. $\mathrm{X}_{1}^{\mathrm{L}}$ and $\mathrm{X}_{1}^{\mathrm{U}}$ are the lower and the upper limits of the design variables[14].

In a study by the author, an optimum shape design algorithm was developed by the coupling of an optimising technique with a boundary element stress analyser for stress minimization of 2D anisotropic structures[5]. Applications of this general purpose computer program to the optimum shape design of bars and holes in plates with anisotropic materials were presented. In this case the objective function is highly non-linear, while the constraints are linear. The optimisation method used was the extended interior penalty function approach, and for unconstrained minimization, the Broydon-Fletcher-Goldfarb-Shanno (BFGS) variable metric method was employed.

In another study by the author[6], an optimisation algorithm was developed to minimize the structural weight of a 2D anisotropic structure while satisfying certain constraints upon stresses and geometry. The boundary element method was used for the stress analysis and also for the shape sensitivity analysis. Since both the objective function and constraints are non-linear, the feasible direction method(FDM) was employed[14-16].

In another study by the author[7], an advanced version of the aforementioned algorithm was produced to find the optimum shape of an anisotropic structure for the highest stiffness and minimum weight. In this case the elastic compliance of the structure was minimized while there were some constraints upon the stresses and weight. In all the procedures mentioned above the design variables were the coordinates of a series of points defining the shape of the variable part of the boundary. Hermitian cubic spline functions were used to represent boundary shapes that offer considerable advantages in fitting a wide range of curves and in 
Tafreshi, A. Jan 2006 In : Engineering Analysis with Boundary Elements. 30, 1, p. 1-13 12 p.

the automatic remeshing process. Hermitian cubic spline functions, are combinations of piecewise cubic curves with continuous first and second derivatives at the ends of each curve. This provides a flexible and compact method for defining boundary geometry using a small number of design variables. They also reduce the need for optimisation constraints to avoid impractical design during the optimisation procedure[1-7].

In the present study, to find the optimal shape of a structure for the highest stiffness, the elastic compliance has been minimized when the weight of the structure remains unchanged. The purpose is to find the optimum positions and orientations of a series of voids in a twodimensional anisotropic structure. Therefore, $\mathrm{X}$ in equation 32 is a vector of shape variables which defines the translations and orientations of the voids within the structure. It should be noted that each shape variable is associated with the coordinates of a series of boundary nodes, related to the boundary element discretization of the structure. The constraints are imposed on the maximum allowable stress. There may also be some side constraints related to the position and orienation of each void. During the optimisation process the original shape and, therefore, the boundary element discretization of each movable void, remains unaltered, with respect to its local coordinate system, whereas the void may be repositioned or reoriented with respect to the global coordinate system. Here, the elastic compliance is treated as the objective function whereas stresses are treated as the inequality constraints. FDM is employed as the optimisation algorithm.

The FDM was first proposed by Zoutendijk[15] and later, Vanderplaats et al[16] applied the algorithm on design optimisation of space truss structures. Since then, the FDM has been one of the most popular methods for finite element analysis based structural optimisation[14]. It is also shown that FDM can be successfully used for boundary element analysis based structural optimisation[1-7]. 
Tafreshi, A. Jan 2006 In : Engineering Analysis with Boundary Elements. 30, 1, p. 1-13 12 p.

\section{NUMERICAL RESULTS}

To apply the boundary element method for the optimum feature positioning of twodimensional composite structures, a general-purpose computer program has been developed. This is an advanced version of a shape optimisation program which was already produced by the author for the minimization of the elastic compliance of anisotropic structures, while satisfying some constraints upon weight, stresses and geometry [7]. In this study the weight remains constant throughout the optimisation process, while the positions and orientations of a series of voids of arbitrary shapes will be determined, for the minimum elastic compliance and maximum stiffness. The constraints will be on the maximum stress and also some side constraints related to the positioning of the voids. The program uses an iterative technique and involves three major steps within each iteration: a) an analysis of the stresses, displacements and elastic compliance of structure for a given design b) sensitivity analysis of the elastic compliance and stresses, corresponding to possible changes in design c)improvements to the design by repositioning and reorientation of the voids within the structure.

The accuracy of the sensitivity analysis of the produced program, with respect to the positioning and orientation of the features, is verified by the analysis of a thin flat plate with a circular hole or a square cutout. In another example the optimum positions of two nonidentical circular holes, in a thin flat plate subject to linear distributed loads varying along its edges, are obtained. Five different materials[17-19] are used to investigate the effect of engineering constants on the sensitivity analysis and optimum shape design of the components. Every component is being treated as a lamina that has four engineering constants $E_{1}, E_{2}, G_{12}$ and $v_{12}$, with a lamina orientation angle of zero. See Table 2. Material 1 is isotropic but it is assumed as if it is anisotropic, $\mathrm{E}_{1}=\mathrm{E}_{2}, \mathrm{G}_{12}=\mathrm{E}_{1} / 2\left(1+v_{12}\right)$. The properties of materials 2,3 and 4 are as follows: for material 2, $E_{1} / E_{2}=13.36, G_{12} / E_{2}=0.58$ and $v_{12}=0.295$; 
Tafreshi, A. Jan 2006 In : Engineering Analysis with Boundary Elements. 30, 1, p. 1-13 12 p. for material $3 \mathrm{E}_{1} / \mathrm{E}_{2}=1.0, \mathrm{G}_{12} / \mathrm{E}_{2}=2.94$ and $v_{12}=0.845$; for material $4 \mathrm{E}_{1} / \mathrm{E}_{2}=2.42, \mathrm{G}_{12} / \mathrm{E}_{2}=0.24$ and $v_{12}=0.22$; for material $5 \mathrm{E}_{1} / \mathrm{E}_{2}=40, \mathrm{G}_{12} / \mathrm{E}_{2}=0.492$ and $v_{12}=0.25$.

\subsection{A thin flat plate with a circular hole}

Fig.2 shows a thin flat plate with a central circular hole in a uniaxial stress field. This plate with isotropic material properties, was analysed by Dems and Mroz[20]. They found the optimum position of the hole, along the direction normal to the applied load, by minimization of its elastic compliance, using the finite element method. They observed that the elastic compliance of the plate was minimized when the hole position was offset from the centre of the plate.

Here, the optimum position of the hole in the plate, shown in Fig. 2, with four different anisotropic material properties is obtained. The selected materials are materials 1 to 4 from Table 1. Material 1 is isotropic but in the current analysis it is assumed as if it is anisotropic $\left[\mathrm{E}_{1}=\mathrm{E}_{2}, \mathrm{G}_{12}=\mathrm{E}_{1} / 2\left(1+\mathrm{v}_{12}\right)\right]$. The shape variable is the $\mathrm{y}$ coordinate of the hole's centre. 56 quadratic boundary elements have been used for the analysis, 36 elements on the outer boundary and 20 elements on the inner boundary.

Since the y coordinate of the hole's centre is the only shape variable, a series of analyses have been performed by just changing the location of the hole along the y direction. Using the methods explained in section 4, for the aforementioned plates with different hole positions, the derivative of the elastic compliance has also been computed.

Figs. 3-6 show the variation of the elastic compliance and its derivative with respect to the vertical position of the hole's centre for the selected materials. The results shown in Fig. 3 agree very well with the findings of Dems and Mroz [20] for an isotropic plate. It can be seen 
Tafreshi, A. Jan 2006 In : Engineering Analysis with Boundary Elements. 30, 1, p. 1-13 12 p. that the elastic compliance has stationary conditions at three different points, at the plate's centre and two other locations offset from the plate's centre, $y \approx \pm 2.0$. The zero values of the derivatives at these locations confirm the accuracy of the results. It can be observed that the optimum position of the hole, based on the minimum value of the elastic compliance, is achieved when the hole is located offset from the plate's centre.

As shown in Fig. 5, the variation of the elastic compliance and its derivative for material number 3 have similar trends to the variation of the elastic compliance and its derivative for material number 1, respectively. It can also be observed that the optimum position of the hole's centre for material number 3 is located offset from the centre of the plate. In comparison with the optimum position of the hole's centre, for the isotropic plate, the optimum position of the hole's centre for material number 3 is slightly further away from the centre, $y \approx \pm 2.5$.

Figures $4 \mathrm{a}$ and $6 \mathrm{a}$ show that the variation of elastic compliance, with respect to the $\mathrm{y}$ coordinate of the hole's centre, has similar trend for materials number 2 and 4 . For these materials, a similar trend of variation can also be observed for the derivative of elastic compliance. See Figs. $4 \mathrm{~b}$ and $6 \mathrm{~b}$. It can be seen that for material numbers 2 and 4 , the stationary conditions for the elastic compliance and its minimum value are only achieved when the hole is located at the centre of the plate. The zero value of the derivative of the elastic compliance at the plate's centre, for these materials, confirms the accuracy of the solution.

Fig. 7 shows a thin flat plate in a uniaxial stress field with a hole which is originally located offset from the centre of the plate, both in the $\mathrm{x}$ and $\mathrm{y}$ directions. The coordinates of the original position of the circle are $x=5.0$ and $y=5.0$, respectively. To validate the accuracy of 
Tafreshi, A. Jan 2006 In : Engineering Analysis with Boundary Elements. 30, 1, p. 1-13 12 p.

the produced optimisation program, the optimum position of the hole in the plate, shown in Fig. 7, is obtained. Material numbers 1 and 2 are selected for the analysis. In this case the $x$ and y coordinates of the centre of the hole are selected as the shape variables. The optimum locations of the hole, obtained using the optimisation program, agree very well with the results presented in Figs. 3 and 4. As shown in Figs. 3 and 7, for material number 1, the optimum positions of the hole's centre are at $x=0$. and $y \approx \pm 2.0$, respectively. For material number 2, as shown in Figs. 4 and 7, the optimum position of the hole is at the plate's centre. The variation in compliance, as a proportion of the initial compliance during convergence to the optimum for each selected material, is shown in Fig. 8. The analysis was carried out in 9 iterations for material number 1 , with $33 \%$ reduction of the elastic compliance, and 9 iterations for material number 2 , with $60 \%$ reduction of the elastic compliance.

Next, the design sensitivity analysis of the produced program is validated with respect to the orientation angle of a typical void in an anisotropic structure. Fig. 9 shows a thin flat plate with a central square cutout in a uniaxial stress field. Here, the objective is to find the derivative of the elastic compliance with respect to the orientaion angle( $\theta)$ of the cutout. Since there is only one shape variable, a series of analyses have been performed by changing the orientaion angle of the cutout in the plate from zero to ninty degrees. For the aforementioned plates, with different orientation angles of the cutout, the derivative of the elastic compliance with respect to the angle $(\theta)$ has also been computed. For the sake of brevity, only two materials are selected for the analysis: materials 1 and 2. Figs.10a and 11a show the variation of the elastic compliance with respect to the rotation angle of the cutout for the selected materials. The derivative of the elastic compliance, with respect to the rotation angle of the cutout for the same materials, are shown in Figs. 10b and 11b. It can be observed that for both materials, the stationary conditions and the minimum value of the elastic compliance are obtained when the edges of the cutout are parallel to the edges of the 
Tafreshi, A. Jan 2006 In : Engineering Analysis with Boundary Elements. 30, 1, p. 1-13 12 p.

plate. See Fig. 9. This agrees with the zero value of the derivative of the elastic compliance when the orientation angle is 45 degrees. See Figs. $10 \mathrm{~b}$ and $11 \mathrm{~b}$.

56 quadratic elements were used for the analysis, 36 elements on the outer boundary and 20 elements on the inner boundary.

\subsection{A thin flat plate with two circular holes subject to linear distributed loads}

Fig.12 shows a rectangular thin flat plate with two circular holes. The radius of the right hole is twice the radius of the left hole. The plate is subject to the distributed loads varying linearly along its edges. The objective is to find the optimum locations of the holes for four different material properties, materials $1,2,3$ and 5. The initial positions of the holes are shown in Fig.12. The $\mathrm{x}$ and $\mathrm{y}$ coordinates of the centres of both holes are selected as shape variables. The plate has been analysed using 76 quadratic boundary elements, 36 elements on the outer boundary and 20 elements on the boundary of each hole.

Fig. 13 shows the elastic compliance $\left(\mathrm{E}_{\mathrm{s}} / \mathrm{E}_{\mathrm{s} 0}\right)$ iteration history for the plate for the selected materials. For each selected material, the optimisation procedure was carried out with the maximum allowable limit on the stress being 1.1 times the maximum stress of the original geometry. The analysis of material 1 was completed in 14 iterations, with $5 \%$ reduction of the elastic compliance and the maximum stress of the optimised shape was about $84 \%$ of the original shape. For material 2, the analysis was completed in 12 iterations with $16 \%$ reduction of the elastic compliance and the maximum stress has been reduced by $22 \%$. For material 3 the elastic compliance and the maximum stress of the plate were reduced by $2 \%$ and $10 \%$, respectively. In this case the optimum shape was obtained in 8 iterations. The greatest reduction of the elastic compliance was $27 \%$ for material number 5 , which was achieved in 14 iterations. The maximum stress was also reduced by $26 \%$. 
Fig. 14 shows the original and optimum positions of each hole in the plate for the selected materials. Table 2 shows the original and optimum coordinates of each hole's centre. It can be observed that, irrespective of the material properties, for each optimal design the line joining the centres of the holes is almost parallel to the $\mathrm{x}$ axis.

\section{SUMMARY AND CONCLUSION}

Following a brief review of the mathematical basis of the boundary integral equation method for two-dimensional elastic anisotropic materials, analytical differentiation of the boundary integral equation was carried out with respect to the positions of the boundary nodes. By the application of design velocity fields, the shape variables, such as feature positions, were related to the relevant boundary nodes. Shape design sensitivity analysis was performed to compute the derivatives of displacements, stresses, and elastic compliance with respect to changes of shape variables associated with the positions and orientations of the voids of arbitrary shapes within an anisotropic structure. To maximize the stiffness, the elastic compliance was minimized while satisfying some constraints upon stresses and geometry. The weight of the structure remained constant throughout the optimisation procedure. The numerical optimisation algorithm used was the feasible direction method, together with the golden section method for the one-dimensional search. The sensitivity analysis and optimization algorithm were validated using the test cases with known solutions. A couple of examples have been analysed and the results are presented. Five different anisotropic materials were employed for the analysis. It is shown that the optimum locations and orientations of voids in a composite structure, for maximum stiffness, not only depend on the loading conditions but also on the material properties. 
Tafreshi, A. Jan 2006 In : Engineering Analysis with Boundary Elements. 30, 1, p. 1-13 12 p.

\section{REFERENCES}

1. A. Tafreshi, "Design optimisation using the boundary element method", $\mathrm{PhD}$ Thesis, Mechanical Engineering Department, Imperial College of Science, Technology and Medicine, University of London, 1990

2. A. Tafreshi and R.T. Fenner, "Design optimisation using the boundary element method", J. Strain Analysis, V26, N4, pp231-241, 1991

3. A. Tafreshi, and R.T. Fenner, "Design sensitivity analysis using the boundary element method”, J. Strain Analysis, V28, N4, pp 283-291, 1993

4. A. Tafreshi and R.T. Fenner, "General-purpose computer program for shape optimisation of engineering structures using the boundary element method", Computers and Structures, V56, No. 5, pp 713-720, 1995

5. A. Tafreshi, " Shape design sensitivity analysis of 2D anisotropic structures using the boundary element method", Engineering Analysis with Boundary Elements, V26, pp237-251, 2002

6. A. Tafreshi,"'Shape optimisation of two-dimensional anisotropic structures using the boundary element method", Journal of Strain Analysis, V38, 3, 219-232, 2003

7. A.Tafreshi, "Optimum shape design of composite structures using the boundary element method", AIAA Journal, 2005; 43(6), 1349-1359

8. R. F. Gibson, "Principles Of Composite Material Mechanics", McGraw-Hill, Inc., 1994

9. S.G. Lekhnitskii, "Theory of Elasticity Of An Anisotropic Elastic Body", HoldenDay, San Francisco, California, Inc. 1963

10. M.D. Snyder and T.A. Cruse, "Boundary-integral equation analysis of cracked anisotropic plates”, Int. J. Fracture, V11, No. 2, pp315-328, 1975 
Tafreshi, A. Jan 2006 In : Engineering Analysis with Boundary Elements. 30, 1, p. 1-13 12 p.

11. R.B. Wilson and T.A. Cruse, "Efficient implementation of anisotropic three dimensional boundary integral equation stress analysis", International Journal for Numerical Methods in Engineering, Vol.12, pp1383-1397, 1978

12. C.L. Tan, C.L. Gao and F.F. Afagh, "Anisotropic stress analysis of inclusion problems using the boundary integral equation method”, J. Strain analysis, V27, No. 2, 67-76, 1992

13. T.A. Cruse, "Boundary Element Analysis in Computational Fracture Mechanics", Kluwer, Dordrecht, Academic Publishers, 1988

14. G.N. Vanderplaats, "Numerical Optimisation Techniques for Engineering Design with Applications, McGraw-Hill, London 1984

15. G.Zoutendijk, "Methods of feasible directions", Elsevier, Amsterdam,1960

16. G.N.Vanderplaats and F.Moses, "Structural optimisation by methods of feasible directions”, Journal of Computers and Structures, 3(4), pp739-755, July 1973

17. A. Tafreshi, "Efficient modelling of delamination buckling in composite cylindrical shells subject to axial compression”, J. Composite Structures 64/3-4, 511-520, 2004

18. A. Tafreshi, "Delamination buckling and post-buckling analysis of composite cylindrical shells subject to external pressure", J. thin-walled structures, 42/10, 13791404,2004

19. A. Tafreshi, "Delamination buckling and post-buckling analysis of composite cylindrical shells subject to axial compression and external pressure", Composite structures, In press(available online)

20. K. Dems and Z. Mroz, "Multiparameter structural shape optimisation by the finite element method” Int. J. numer. Methods eng, 13, 247-263, 1978 
Tafreshi, A. Jan 2006 In : Engineering Analysis with Boundary Elements. 30, 1, p. 1-13 12 p.

Table 1 Elastic properties of the selected materials

\begin{tabular}{|l|l|l|l|l|l|l|}
\hline \multicolumn{1}{|}{ Material } & $\mathrm{E}_{11}(\mathrm{GPa})$ & $\mathrm{E}_{22}(\mathrm{GPa})$ & $v_{12}$ & $\mathrm{G}_{12}(\mathrm{GPa})$ & Complex parameters \\
\hline 1 & & & & & $\mu_{1}$ & $\mu_{2}$ \\
\hline 2 & 210.9 & 210.9 & 0.29 & 81.8 & $\mathrm{i}$ & $\mathrm{i}$ \\
\hline 3 & 148.07 & 11.08 & 0.295 & 6.40 & $4.683 \mathrm{i}$ & $0.780 \mathrm{i}$ \\
\hline 4 & 34.2 & 14.1 & 0.22 & 3.4 & $3.059 \mathrm{i}$ & $0.509 \mathrm{i}$ \\
\hline 5 & 276.0 & 6.9 & 0.25 & 3.4 & $8.948 \mathrm{i}$ & $0.706 \mathrm{i}$ \\
\hline
\end{tabular}

Table 2 Original and optimum position of each hole (Fig. 12)

\begin{tabular}{|c|c|c|c|}
\hline & & \\
\hline & & Left hole & Right hole \\
\hline \multicolumn{2}{|l|}{ Initial position } & $X=-5.0$ & $X=5.0$ \\
\hline \multirow{4}{*}{ Optimum position } & Material 1 & $\begin{array}{l}X=-1.28 \\
Y=1.50\end{array}$ & $\begin{array}{l}X=2.21 \\
Y=1.56\end{array}$ \\
\hline & Material 2 & $\begin{array}{l}X=-2.78 \\
Y=1.92\end{array}$ & $\begin{array}{l}X=1.18 \\
Y=1.84\end{array}$ \\
\hline & Material 3 & $\begin{array}{l}X=-4.12 \\
Y=0.19\end{array}$ & $\begin{array}{l}X=3.73 \\
Y=0.36\end{array}$ \\
\hline & Material 5 & $\begin{array}{l}X=-3.72 \\
Y=2.22\end{array}$ & $\begin{array}{l}X=0.70 \\
Y=2.18\end{array}$ \\
\hline
\end{tabular}


Tafreshi, A. Jan 2006 In : Engineering Analysis with Boundary Elements. 30, 1, p. 1-13 12 p.
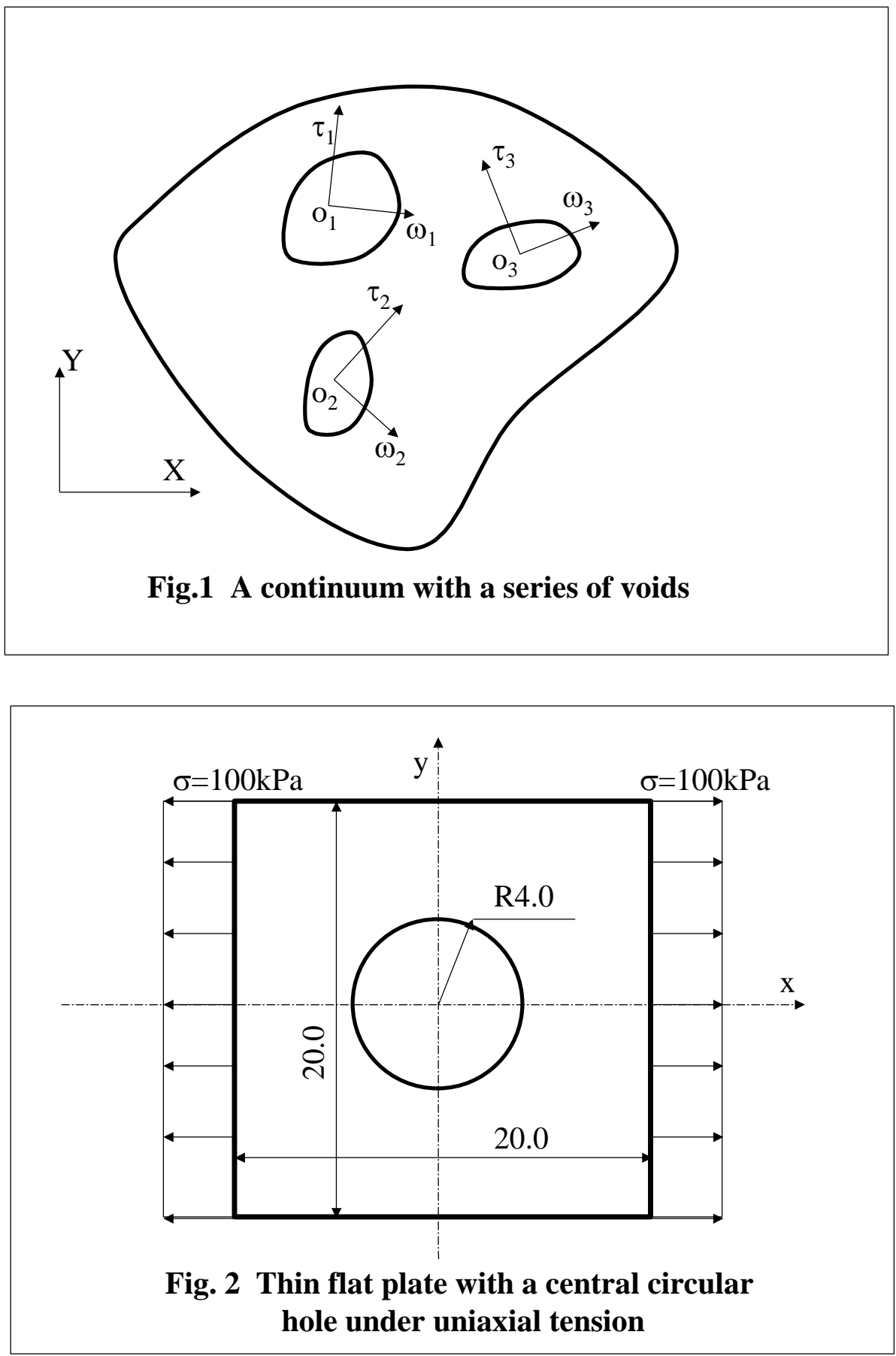

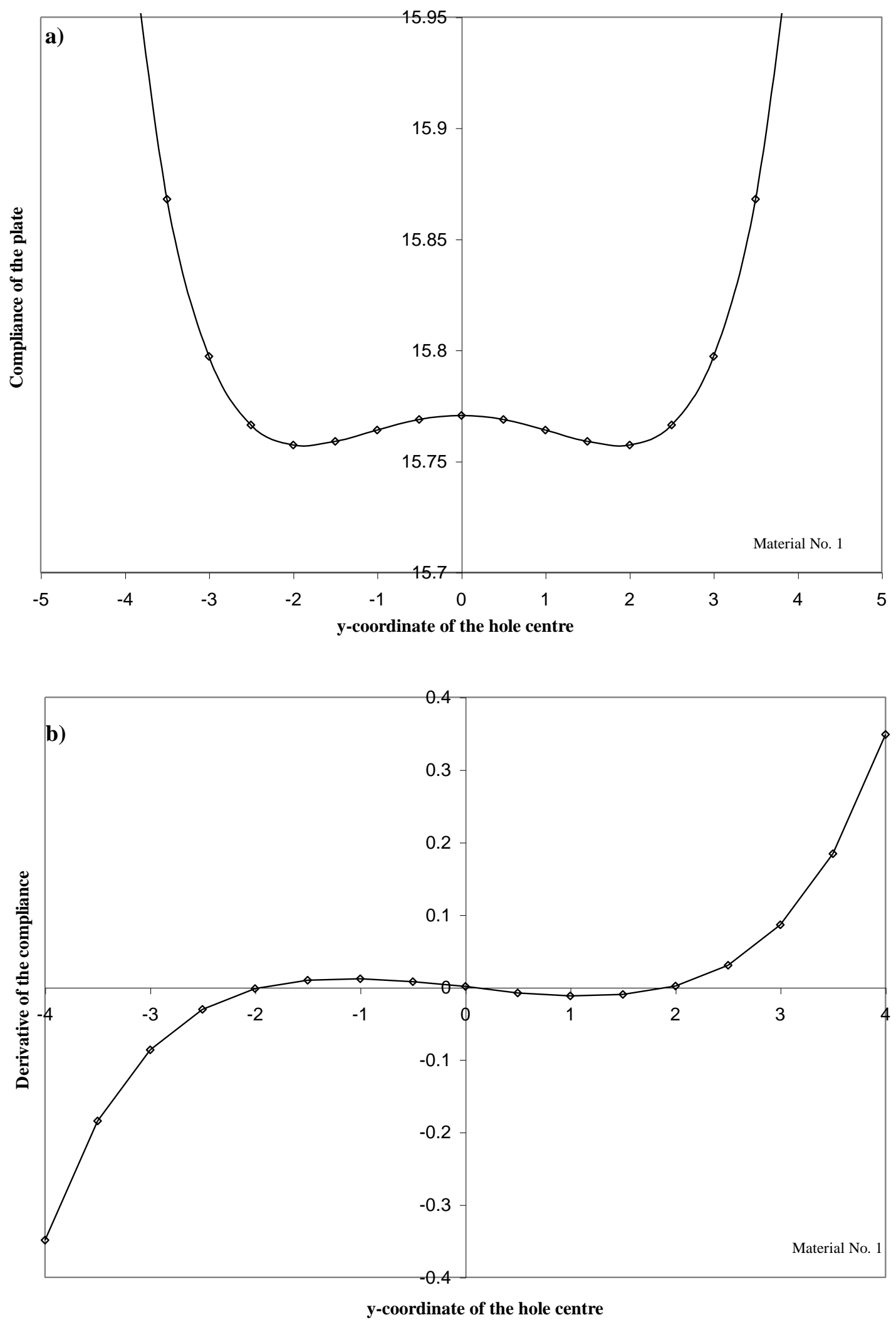

Fig. 3 Variation of the elastic compliance and its derivative with respect to the vertical position of the hole centre for material number 1 

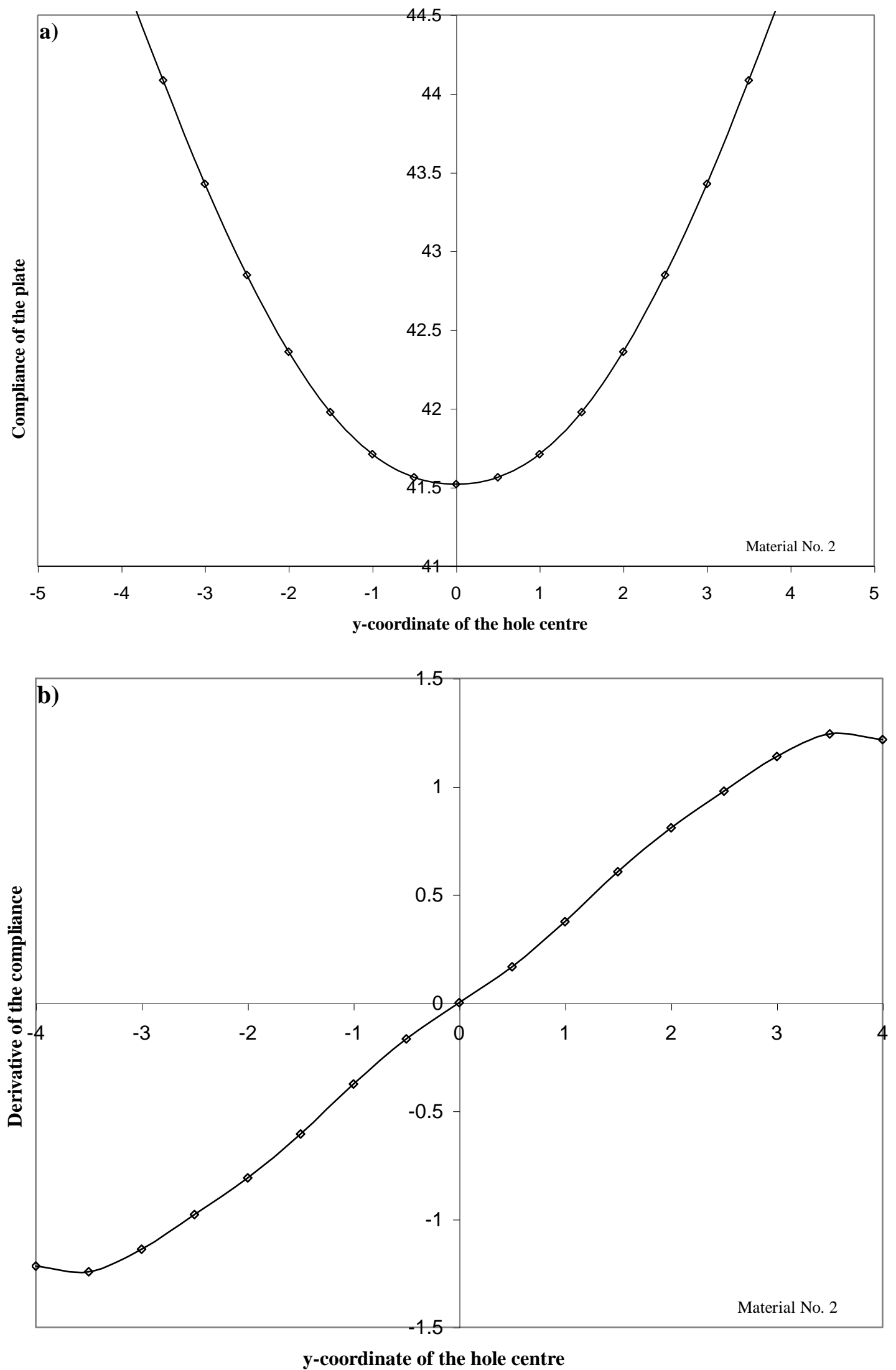

Fig. 4 Variation of the elastic compliance and its derivative with respect to the vertical position of the hole centre for material number 2 

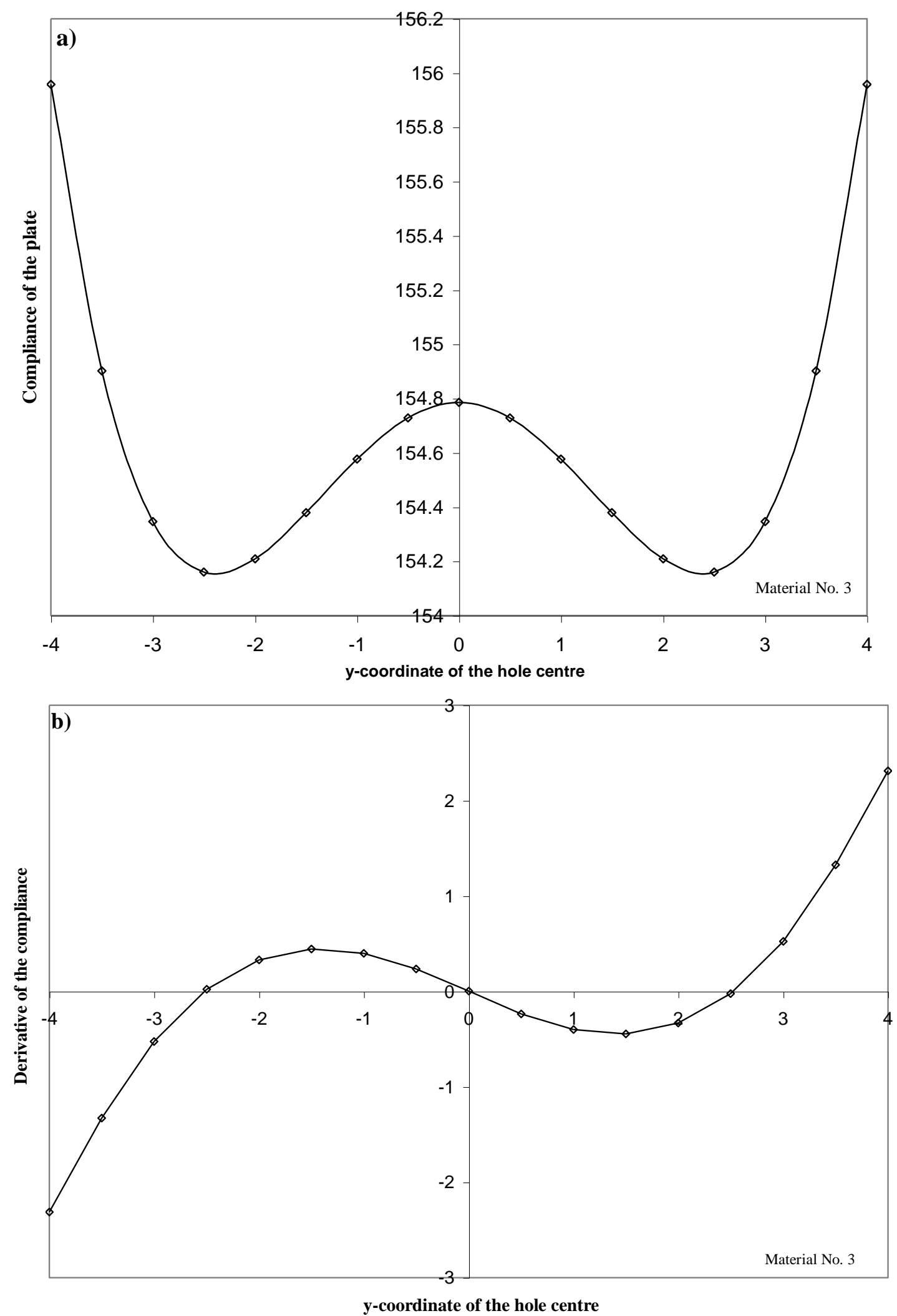

Fig. 5 Variation of the elastic compliance and its derivative with respect to the vertical position of the hole centre for material number 3 

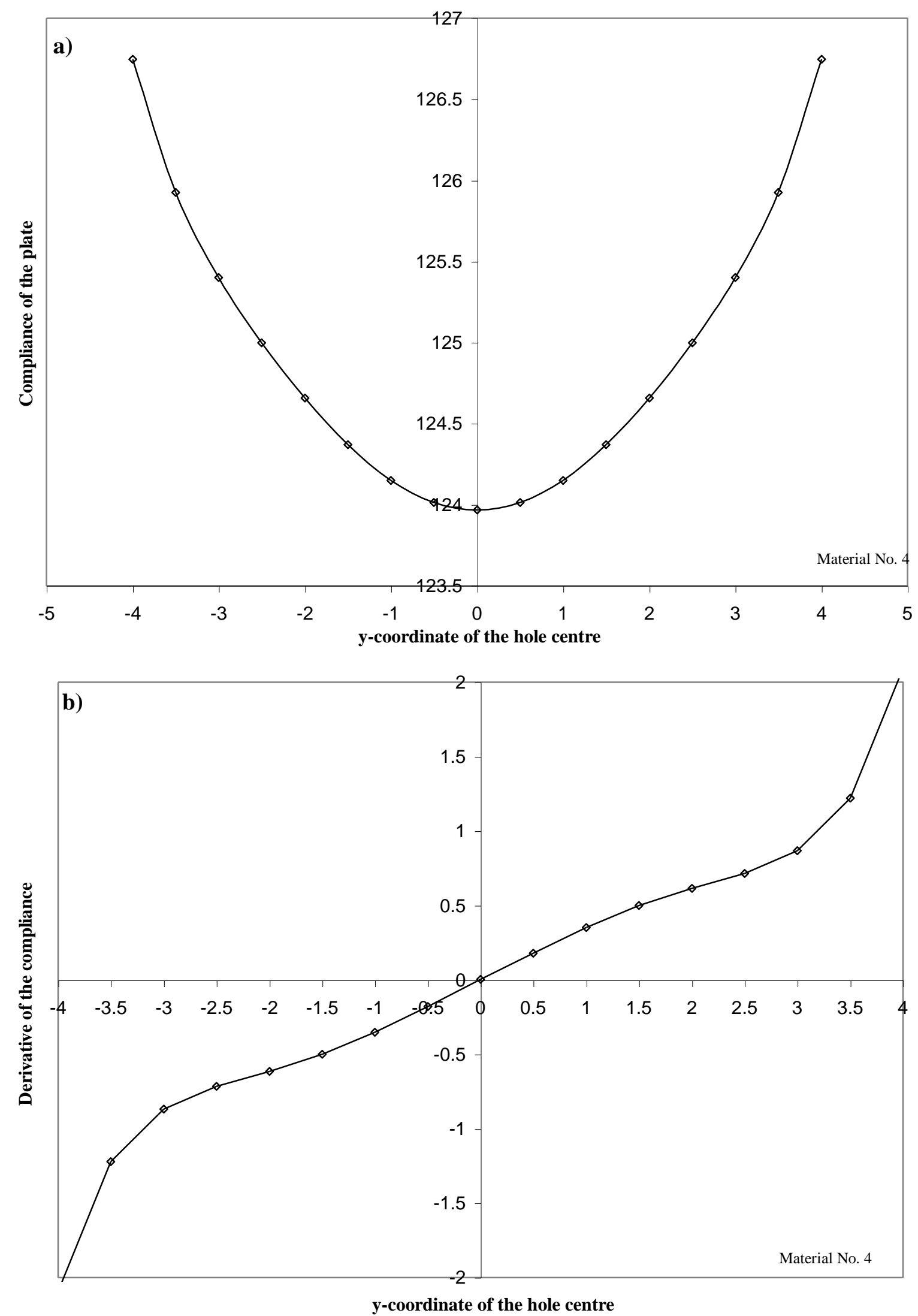

Fig. 6 Variation of the elastic compliance and its derivative with respect to the vertical position of the hole centre for material number 4 


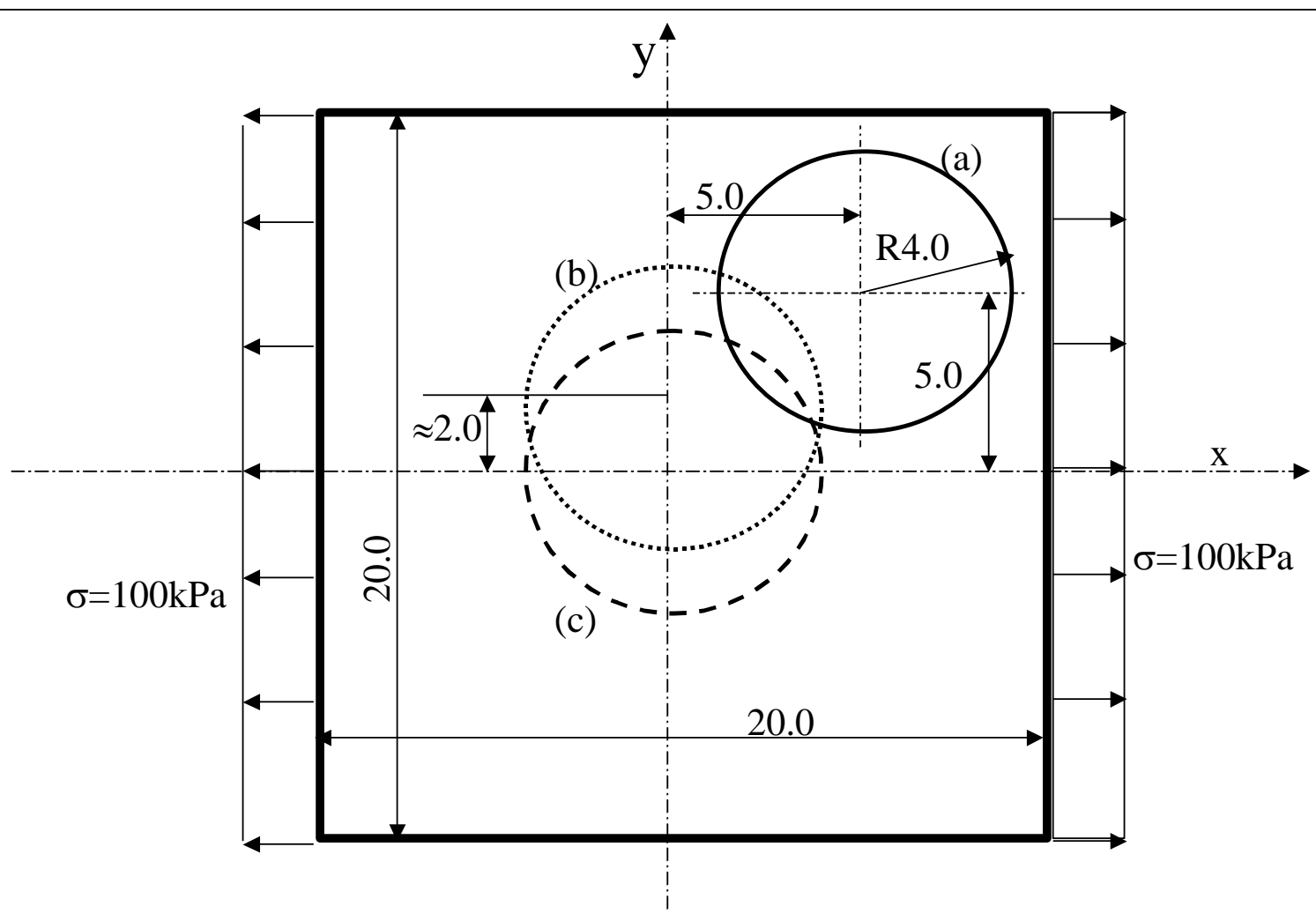

Fig. 7 Optimum position of a circular hole in a thin flat plate under uniaxial loading a) Initial position b) optimum position for material No.1 c) Optimum position for material No. 2 
Tafreshi, A. Jan 2006 In : Engineering Analysis with Boundary Elements. 30, 1, p. 1-13 12 p.

Fig. 8 Elastic compliance iteration history of the plate with a circular hole (Fig.7)

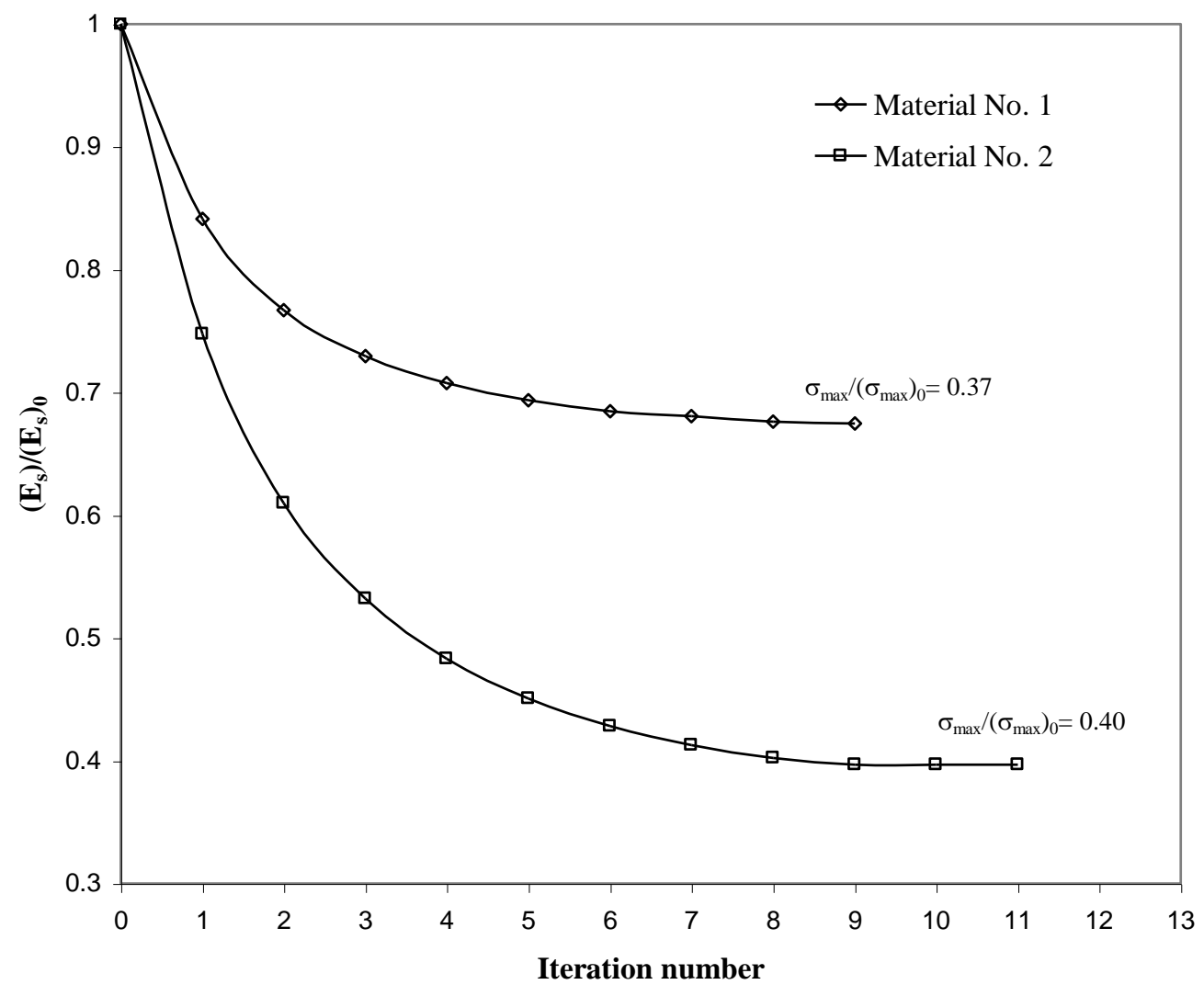




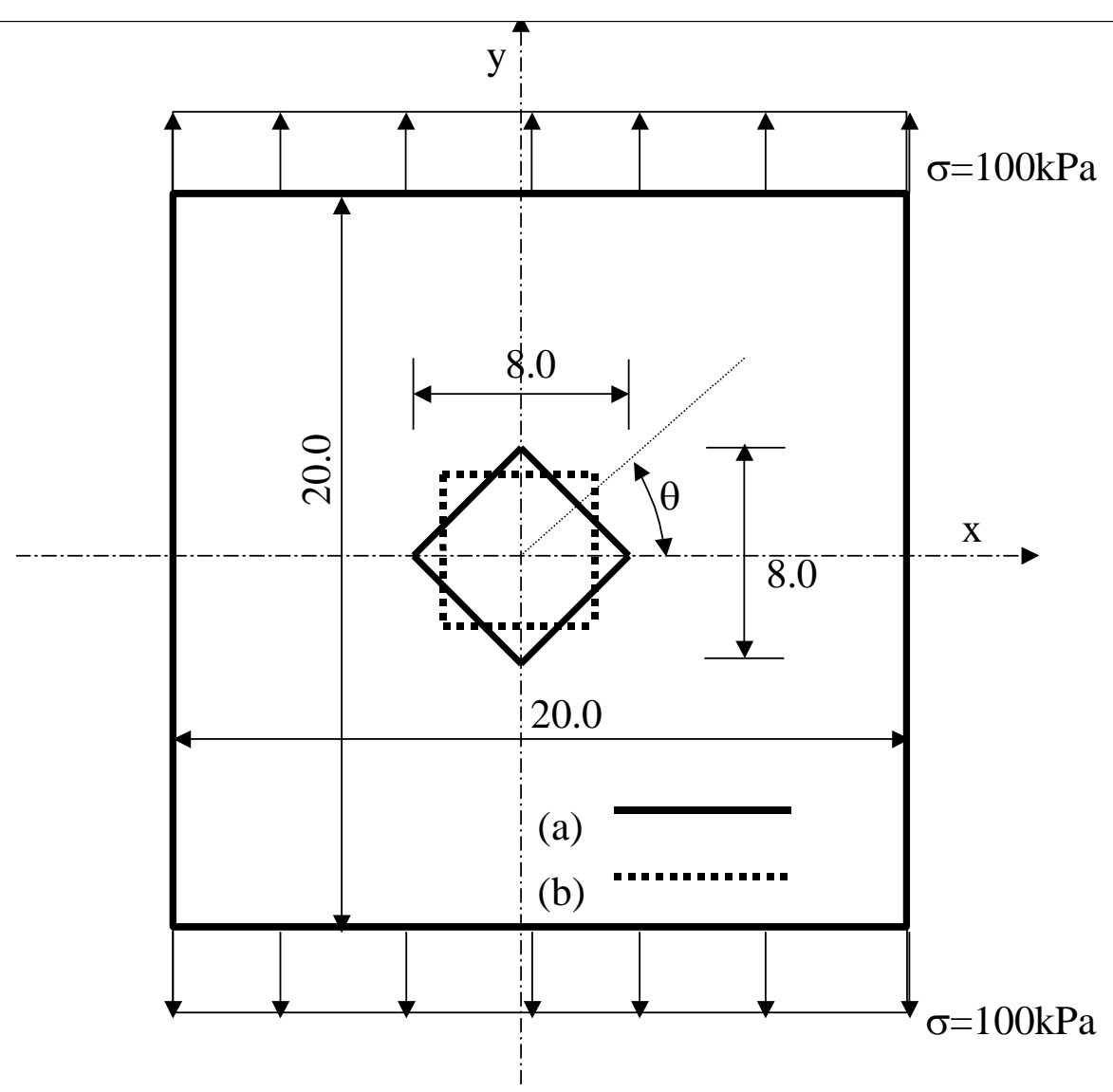

Fig. 9 Thin flat plate with a central square cutout under uniaxial tension a)Initial position b)optimum position 

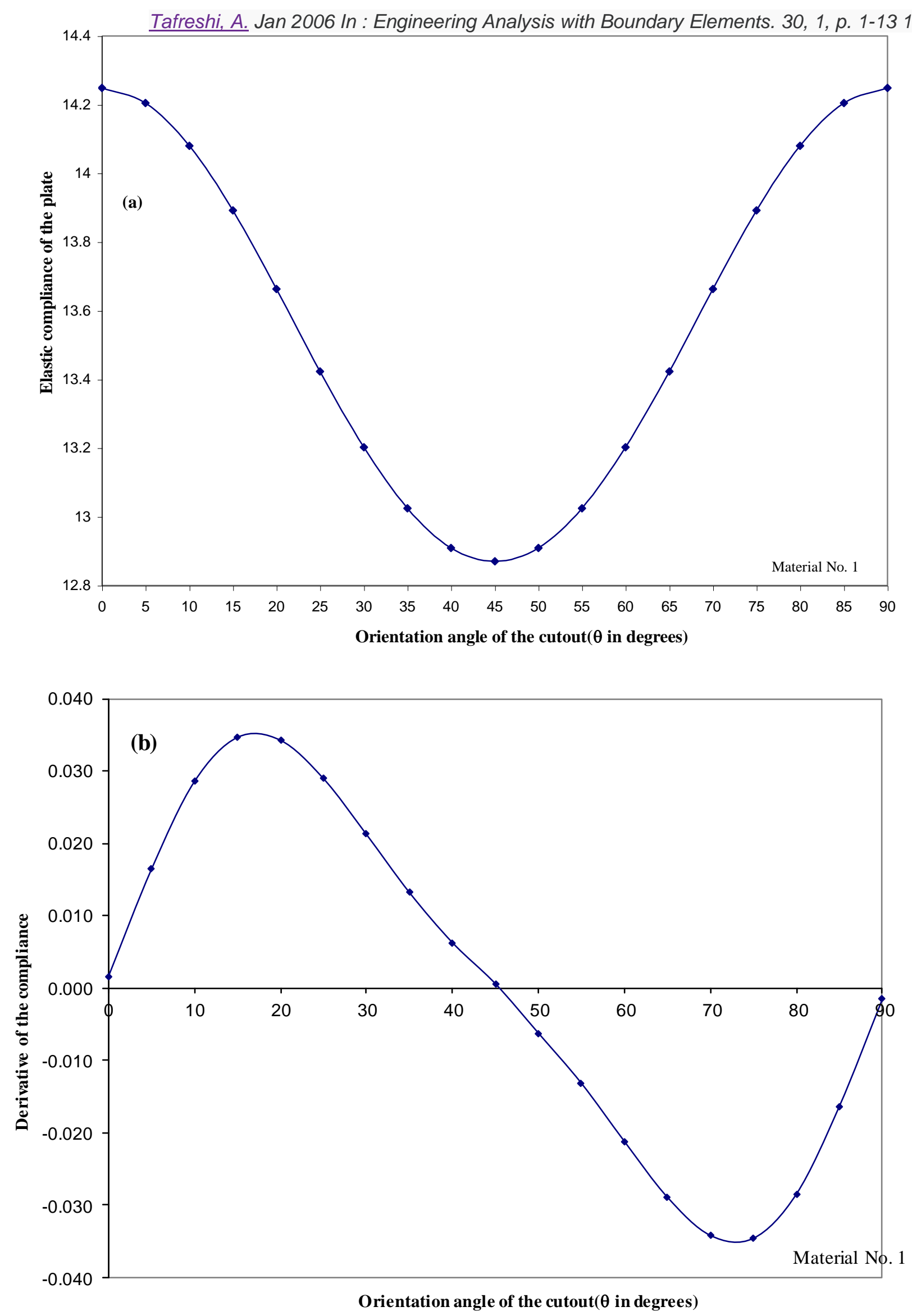

Fig. 10 Variation of the elastic compliance and its derivative with respect to the orientation angle of the cutout for the material number 1 

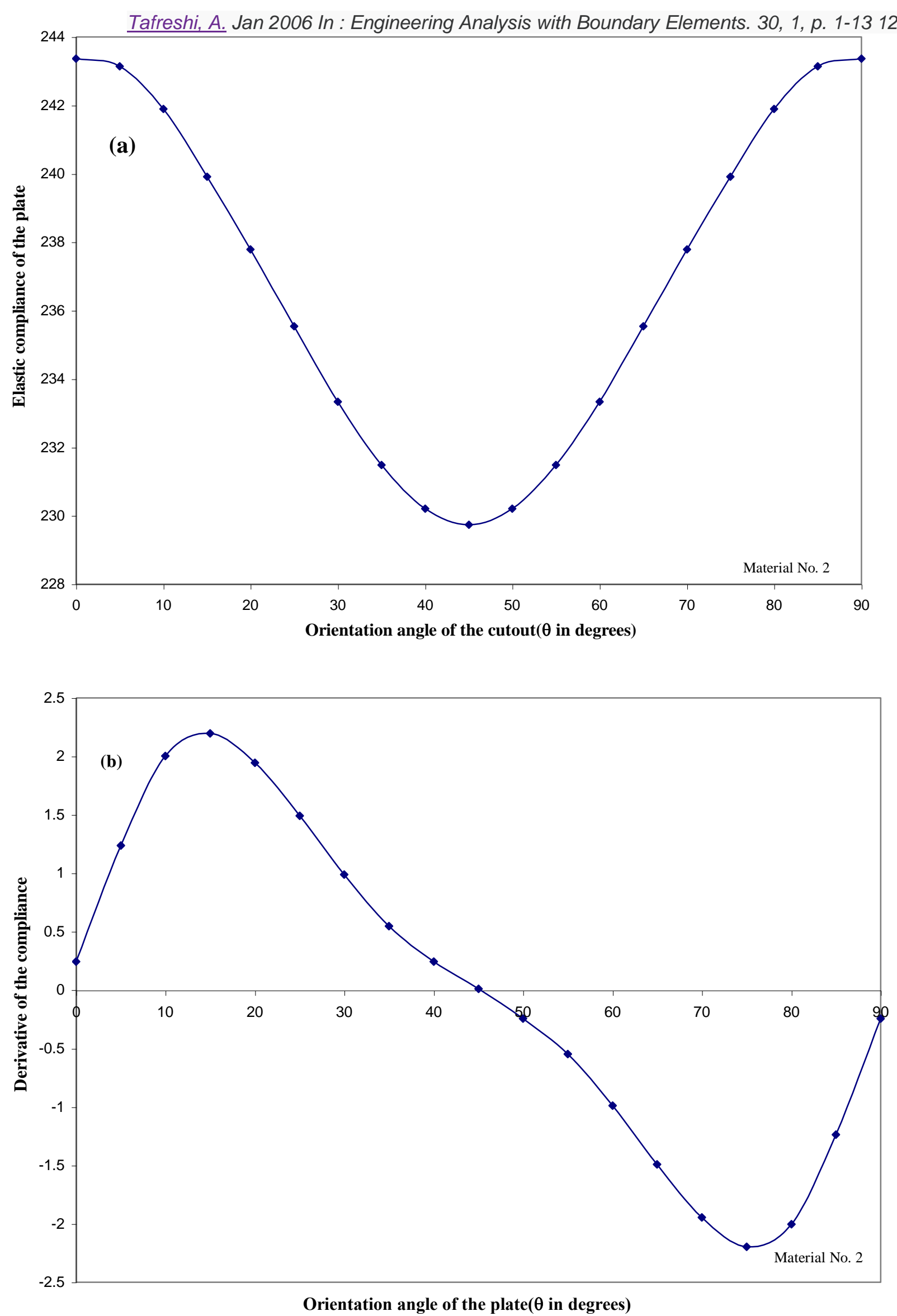

Fig. 11 Variation of the elastic compliance and its derivative with respect to the orientation angle of the cutout for the material number 2 
Tafreshi, A. Jan 2006 In : Engineering Analysis with Boundary Elements. 30, 1, p. 1-13 12 p.

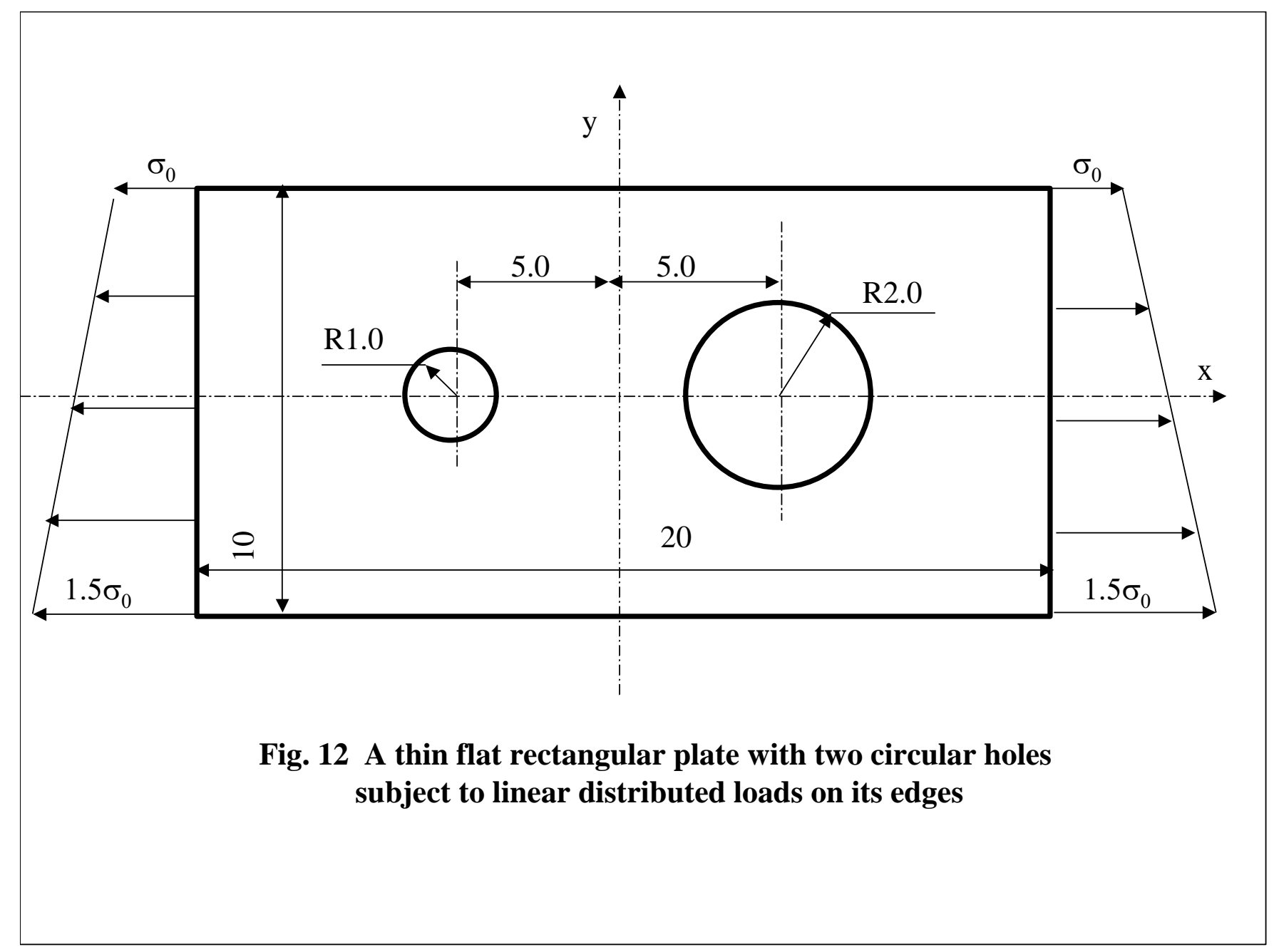


Tafreshi, A. Jan 2006 In : Engineering Analysis with Boundary Elements. 30, 1, p. 1-13 12 p.

Fig. 13 Elastic compliance iteration history of the plate with two circular holes(Fig. 12)

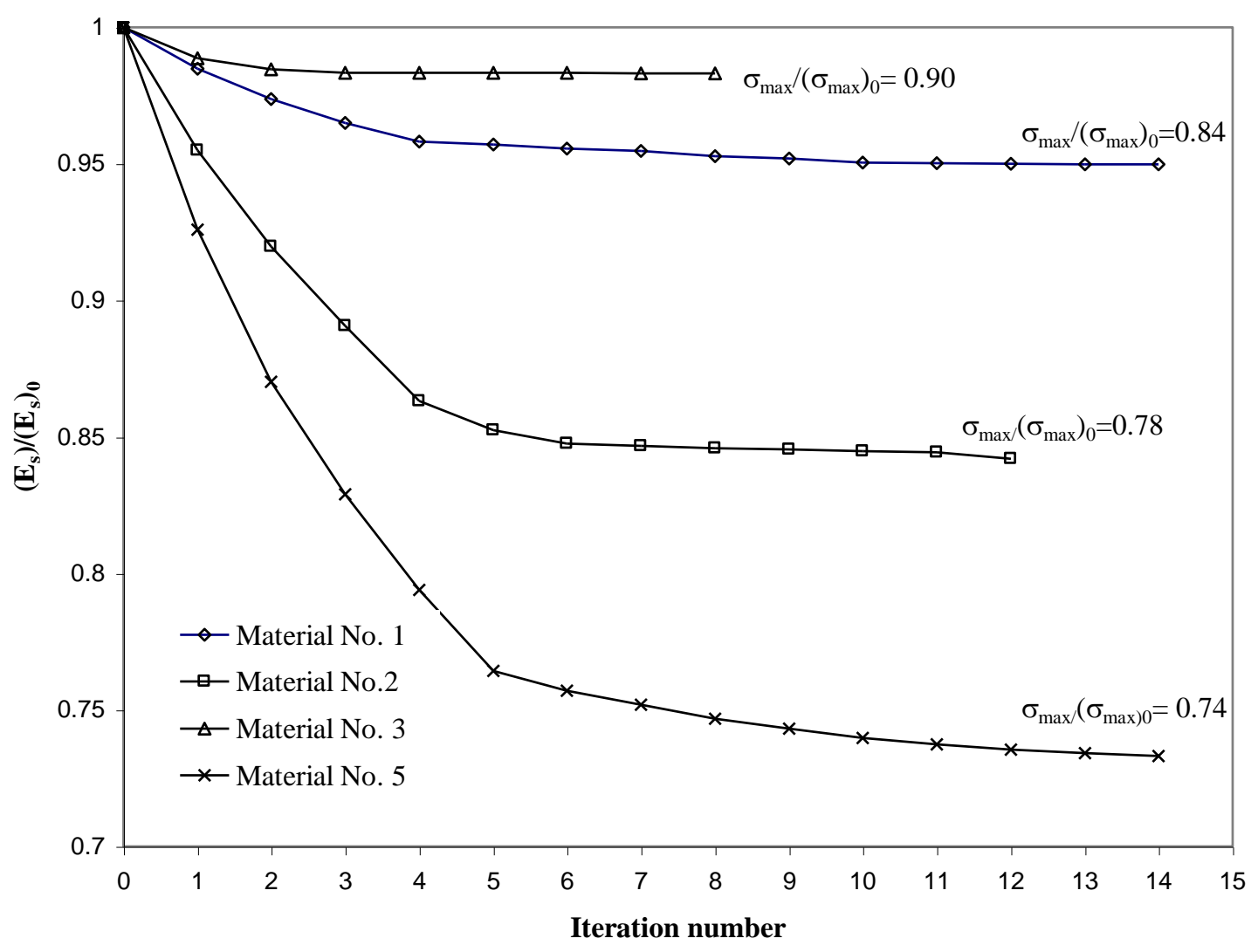




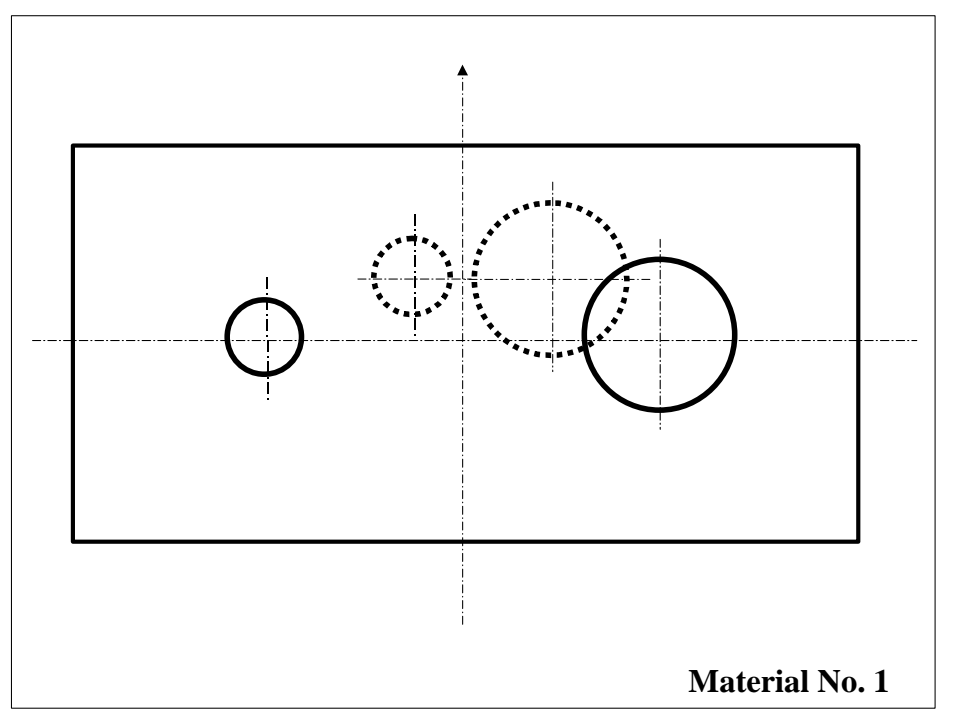

Tafreshi, A. Jan 2006 In : Engineering Analysis with Boundary Elements. 30, 1, p. 1-13 12 p.
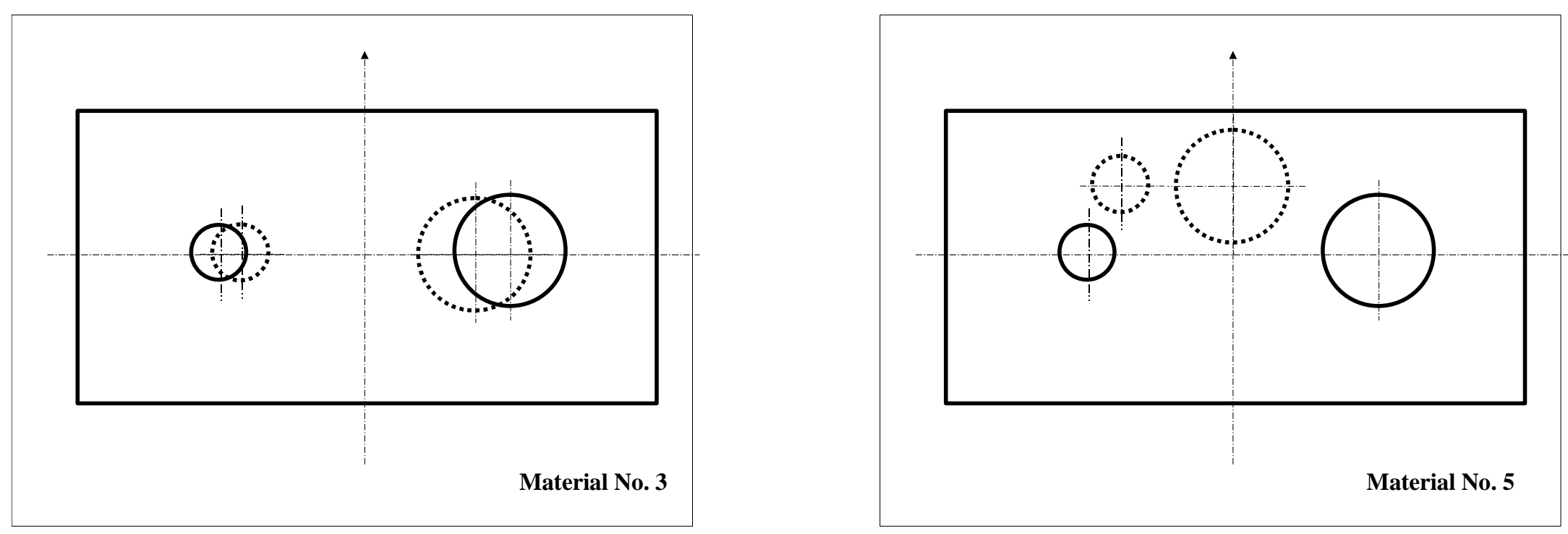

Fig. 14 Optimum positions of the circular holes in the plate subject to linear distributed loads 